\title{
On-campus students' remote use of Internet-based library services and resources: Is there an impact on students' use of the library in-house?
}

\section{A study conducted at the School of Education, University of Waikato}

\author{
by \\ Angela Schönhagen -Bröring
}

Submitted to the School of Communications and Information Management, Victoria University of Wellington

In partial fulfilment of the requirements for the degree of

Master of Library and Information Studies

June 2001

$\mathrm{h}$ 


\section{Acknowledgments}

With special thanks

To my supervisor Dr Dan Dorner for his support and guidance,

To the University of Waikato Library and especially my colleagues in the Education Library for their support and encouragement,

To staff and students of the School of Education who were involved in the survey, and

To Alison Annals, Stuart Bakewell, Andreas and Kirsten Broring for their continued support and patience. 


\section{Contents}

$\begin{array}{lr}\text { Acknowledgments } & 2\end{array}$

$\begin{array}{ll}\text { Contents } & 3\end{array}$

Table of figures $\quad 5$

$\begin{array}{lr}\text { Abstract (keywords) } & 6\end{array}$

$\begin{array}{ll}\text { I. Background } & 7\end{array}$

$\begin{array}{lll}1.1 & \text { Need for the study } & 7\end{array}$

1.2 Value to the organisation and to LIS 8

$\begin{array}{ll}1.3 \text { Analytical framework } & 9\end{array}$

$\begin{array}{lll}1.4 & \text { Statement of the problem } & 11\end{array}$

$\begin{array}{ll}1.5 \text { Hypotheses and research questions } & 12\end{array}$

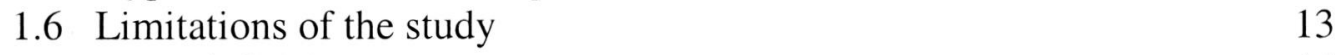

$\begin{array}{lll}1.7 & \text { Term definitions } & 14\end{array}$

II. Review of the literature $\quad 15$

2.1 Impact of remote use $\quad 15$

$\begin{array}{ll}2.2 \text { Characteristics of remote users } & 19\end{array}$

2.2.1 User groups 21

2.2.2 Attitudes towards information technology and library use

2.3 User needs, expectations and satisfaction with remote library services 24

2.3.1 Awareness 25

$\begin{array}{ll}\text { 2.3.2 Training needs } & 27\end{array}$

$\begin{array}{ll}2.3 .3 \text { Accessibility } & 27\end{array}$

III. Design of the study 29

$\begin{array}{lll}3.1 & \text { Research setting } & 29\end{array}$

$\begin{array}{ll}3.2 \text { Sample design } & 30\end{array}$

$\begin{array}{lll}3.3 \text { Data collection } & 32\end{array}$

$\begin{array}{lll}3.4 & \text { Survey instrument } & 33\end{array}$

$\begin{array}{lll}3.5 & \text { Pre-test } & 35\end{array}$

VI. Treatment of the data 37

$\begin{array}{lll}4.1 & \text { Procedure } & 37\end{array}$

4.2 Coding 38

$\begin{array}{lll}4.3 \text { Missing data } & 39\end{array}$

$\begin{array}{lll}4.4 & \text { Procedures used to analyse data } & 39\end{array}$ 
V. Results 42

5.1 Population and sample 42

5.2 Internet access and the use of the Library's Web site 45

5.2.1 Length of Web site use $\quad 48$

5.3 Characteristics of students who use the Library by remote access 49

$\begin{array}{ll}\text { 5.3.1 Gender and Web site use } & 50\end{array}$

5.3.2 Age and Web site use $\quad 53$

5.3.3 Status and Web site use $\quad 55$

$\begin{array}{ll}\text { 5.3.4 Year of study and Web site use } & 57\end{array}$

$\begin{array}{ll}\text { 5.3.5 Programme and Web site use } & 59\end{array}$

5.3.6 Part-time and full-time study and Web site use $\quad 64$

5.4 Impact of remote Library use on the use of the Library in-house 66

5.4.1 Services and resources used in-house $\quad 66$

5.4.2 Services and resources used by remote access 68

5.4.3 Frequency and lengths of in-house library visits $\quad 69$

5.4.4 Frequency and lengths of remote library visits 73

5.4.5 Changes to the number of visits and time spent in the Library $\quad 76$

5.4.6 Preparation of in-house library visits by remote access $\quad 78$

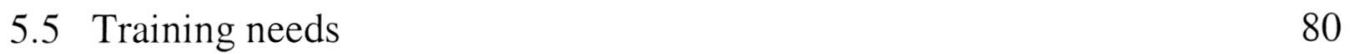

$\begin{array}{ll}\text { VI. Discussion } & 82\end{array}$

6.1 Population and sample $\quad 82$

6.2 Internet access and the use of the Library's Web site 83

6.3 Characteristics of remote users $\quad 88$

6.3.1 Gender, age and status $\quad 88$

6.3.2 Year of study, programme and full-time/part-time study 91

6.4 Impact of remote Library use on the use of the Library in-house 94

$\begin{array}{ll}\text { VII. Conclusion } & 101\end{array}$

$\begin{array}{ll}\text { VIII. Recommendations for further research } & 104\end{array}$

$\begin{array}{lr}\text { IX. Bibliography } & 106\end{array}$

X. Appendices

Appendix 1 Questionnaire and cover letter 110

Appendix 2 School of Education statistics 115 


\section{List of figures}

Tables

Page

Table 1 - Use of the Internet by undergraduate and graduate students

Table 2 - Where the Internet is accessed by undergraduate and graduate students

Table 3 - Students' use of the Library's Web site by remote access by status

Table 4 - Some characteristics of remote users by gender

Table 5 - Some characteristics of remote users by age

Table 6 - Some characteristics of remote users by status 57

Table 7 - Some characteristics of remote users by year of study 59

Table 8 - Some characteristics of remote users by programme 63

Table 9 - Library services/resources used in-house by remote and in-house only users 68

Table 10 - Library services/resources used by remote access $\quad 69$

Table 11 - Frequency of Library visits by remote and in-house only users $\quad 70$

Table 12 - Time spent in the Library by remote and in-house only users $\quad 71$

Table 13 - Changes to the frequency of visits and time spent in the Library by remote 78 users

Table 14 - Frequency of visits, time spent in-house and preparation by remote access $\quad 80$

Table 15 - Preferred formats of training 81

\section{Charts}

Chart 1 - Reasons given why the Library's Web site is not used 48

Chart 2- Length of Web site use $\quad 49$

Chart 3 - Web site use by gender $\quad 51$

Chart 4 - Web site use by age category $\quad 54$

Chart 5 - Web site use by status $\quad 56$

Chart $6-$ Web site use by year of study $\quad 58$

$\begin{array}{ll}\text { Chart } 7-\text { Web site use by programme } & 62\end{array}$

Chart 8 - Web site use by full-time or part-time study 65

Chart 9 - Time spent $x$ frequency of visits in-house by in-house only users $\quad 73$

Chart 10 - Time spent $x$ frequency of visits in-house by remote users $\quad 73$

$\begin{array}{ll}\text { Chart } 11 \text { - Frequency of remote Library visits } & 74\end{array}$

$\begin{array}{ll}\text { Chart } 12 \text { - Time spent on remote Library use } & 75\end{array}$

Chart 13 - Time spent $x$ frequency of visits by remote access 76

Chart 14 - Changes to the number of in-house Library visits 77

Chart 15 - Changes to the time spent in the Library 77

Chart 16 - How often are Library visits prepared by remote access $\quad 79$

Chart 17 - Training needs by remote and in-house only users 81 


\begin{abstract}
With the increase of Internet access available to on-campus students and a growing number of Internet-based library services and resources available by remote access, ongoing research is necessary to monitor who the remote users are and whether remote use of the library has an impact on the use of the library in-house.

This study surveyed on-campus students at the School of Education of the University of Waikato. At the beginning of April 2001 a questionnaire was distributed in a number of classes representing the different levels of the main teacher training programmes. Nearly half of all students enrolled in these programmes were surveyed.
\end{abstract}

In line with findings of previous studies, this study found that a greater number of higher level and older students use the library resources and services by remote access. However, there was also evidence that younger students and students at lower levels increasingly use remote access to the library.

The study did not find a clear pattern of how remote use of the library affects oncampus students' use of the library in-house, but identified some trends of remote user behaviour. There was evidence that some remote users are heavier users of the library in-house than on-campus students who use the library in-house only. On the other hand, this study also found that some remote users used the library less in-house as a result of having remote access.

\title{
Keywords: [on-campus students] [Internet-based library services and resources] [remote library use] [in-house library use]
}




\section{Background}

Remote access through the Internet to Internet-based library services and resources became available to users in the mid-1980s, when some library opacs ${ }^{1}$ could be accessed through dial-in telnet connections. Since then changes in technology and the greater availability of computers have dramatically improved access to the Internet. Today, every student at the University of Waikato has a computer account which allows her/him to access Internet-based library services and resources from outside the library through the Library's Web site.

This study examines if and how on-campus students use remote access to the library and whether remote use of Internet-based library services impacts on how students use the library in-house.

\subsection{Need for the study}

The review of the literature revealed that these issues have been addressed in previous research by various studies (see 2.1 and 2.2).

However, in a fast changing environment characterised by constantly improved access to the Internet, an increasing range of Internet-based library resources and services and a greater number of computer-literate students coming to universities, ongoing research is important to monitor if and how use-patterns of on-campus students change and what the impact is on their use of the physical library.

\footnotetext{
${ }^{1}$ Online public access catalogue
} 
With the introduction of distance education at the University of Waikato in January 1997 the Library launched its new web-based catalogue which could be accessed remotely from the Library's web site. In June 2000 remote access was increased to a wide range of citation and full-text databases. As a result, use of the Library's Web site has more than doubled. For example, 32502 "successful requests" were recorded for June and 71793 for August 2000. Also, in 1999 7.7\% (2447) of all recall requests were made through the web-based catalogue which was not available then in-house. These figures indicate that the Library's Web site is increasingly used.

One aspect which was investigated in this study was whether undergraduate students as the largest group of users of academic libraries increasingly use the library by remote access. Findings of previous research consistently found that most undergraduates were in-house library users and only a small number used the library remotely (Ferl and Millsap 1992; Bushallow-Wilbur, de Vinney, and Whitcomb 1996; Hsieh-Yee 1996; and Clougherty et al. 1998).

\subsection{Value to the organisation and to LIS}

As no previous study has been done on remote library use at the University of Waikato $^{2}$, this study gives the library administration some clearer understanding of how on-campus students use the Library's services and resources. This information could be used by library management when planning for:

\footnotetext{
${ }^{2}$ A survey was conducted in 1996 at the University of Waikato Library by Bydder and Harwood (1998), which examined students' expectations and satisfaction with library services. Remote Internetbased library services and resources did not feature in this study.
} 
- Further development of Internet-based library services, for example: e-reference

- Development of training programmes for the use of remote services, including web-based tutorials

- Promotion/marketing of remote services and resources

Within the LIS literature this study updates previous studies, with the qualification that it reflects local conditions as the study was conducted at one institution only (School of Education of the University of Waikato).

Services and resources offered through libraries' web sites vary between institutions. Remote use is dependent on the range of remote services and resources offered by libraries. For this reason the outcome of this study was also influenced by the range of remote services and resources which were available through the University of Waikato Library' Web site.

\subsection{Analytical framework}

A landmark study done by Ferl and Millsap in 1992 on remote use of the MELVYL ${ }^{3}$ library system of the University of California was used as the analytical framework for this study. Although this study does not attempt to replicate the study by Ferl and Millsap, their study had similar research objectives, such as:

- To discover who the remote users of the MELVYL system are and to determine their characteristics

\footnotetext{
${ }^{3}$ The Melvyl system is a union catalogue of the nine campuses of the University of California.
} 
- To determine in-house library versus out-of library usage patterns and how remote use of the MELVYL system impacts on the in-house use of the library

The authors developed a questionnaire which was given to remote users only. The responses were then analysed using descriptive statistics, and results for each question were presented in separate tables, as a way of presenting the results for each question clearly. In this study a combination of tables and charts was used to present the results.

This study differs from Ferl and Millsap's (1992) study in the following points:

- User population: on-campus students of the School of Education (University of Waikato) were surveyed, whereas Ferl and Millsap (1992) looked at all users of the MELVYL system who used the system by remote access. Separate statistics were kept for campus affiliated and other users.

- Presentation of the questionnaire: The questionnaire was handed out to students of the SOE on campus in selected classes, whereas Ferl and Millsap made the questionnaire available online.

- Research purpose: This study elaborates on Ferl and Millsap's (1992) attempt to determine how remote use of the library impacts on in-house library use patterns. Ferl and Millsap (1992) measured only changes to the frequency of in-house library visits and not to the amount of time spent or the tasks performed in the library. 


\subsection{Statement of the problem}

The purpose of this study is to determine the number and characteristics of on-campus students of the School of Education (University of Waikato) who use the library by remote access through the Library's Web site and to discover whether remote use of the Library has an impact on how these students use the Library in-house.

1. Sub-problem

Determine the number and characteristics of on-campus students of the School of Education (University of Waikato) who use the Library's resources and services by remote access through the Library's Web site.

2. Sub-problem

Determine on-campus students' use-patterns of library services and resources inhouse and by remote access through the Library's Web site.

3. Sub-problem

Determine if and how remote library use affects students' use of the Library in-house. 


\subsection{Hypotheses and research questions}

1. Hypothesis

That the remote usage of the library services and resources through the University of

Waikato Library's Web site by undergraduate on-campus students of the School of

Education is higher than predictions based on the literature.

2. Hypothesis

That no clear pattern can be determined which proves that remote use of library services and resources by on-campus students of the School of Education has an impact on how these students use the Library in-house.

Research questions

1. Where do students gain access to the Internet?

2. What is the number (percentage) of undergraduate and graduate on-campus students using remote access to the Library?

3. Are students aware of the Library's Web site?

4. What are the various characteristics of the students who use the Library by remote access?

5. Which Library services and resources do students use in-house and by remote access respectively? 
6. How often do students visit the Library in-house and how much time do they spend on average at each visit?

7. How often do students visit the Library by remote access and how much time do they spend on average at each visit?

8. Does remote use of the Library change the number of visits to the Library and/or the time spent in the Library?

9. How often are in-house Library visits prepared by remote use of the Library?

\subsection{Limitations of the study}

Limitations:

The study was dependent on:

- Ethical approval of the study

- The willingness of students to participate

- Support from academic staff of the School of Education for distribution of the questionnaire

Delimitations:

- The questionnaire was distributed within selected classes representing the main teacher training programmes offered at the School of Education

- Only on-campus students of the School of Education (University of Waikato) who attended these classes were surveyed 
- The study therefore reflects local conditions

- The survey was done during semester A 2001 in the first two weeks of April, by which time students had settled in and were using the library for research for their assignments.

\subsection{Term definitions}

In this study:

On-campus students refers to students who have physical access to the campus library;

Remote uses are uses of services offered by the library on the electronic network from access points outside the library or its branch libraries (Poll and te Boekhorst 1996);

Remote users are on-campus students who use the campus library in-house and by remote access;

In-house library use refers to the use of the physical library;

In-house only users refers to on-campus students who use only the physical library; and

Resources/services available from the Library's Web site are internet-based resources and services available by remote access, such as the catalogue, a wide range of citation and full-text databases, subject lists/portals of Internet resources, reference service by e-mail, and a range of circulation services, for example recall, interloan and checking borrower records. 


\section{Review of the literature}

A review of the research literature of the last decade revealed that a number of studies have been done relating to remote use of library resources and services by the oncampus population.

In examining the literature the following gaps have been found:

- Few studies look at on-campus undergraduate students as remote users although they comprise the largest body of users of academic libraries

- There is a lack of recent studies, given the fast changing environment

- There are no New Zealand studies focusing on remote use

The research literature covering library services to off-campus (distance) students has not been examined here. These students are another subset of the remote user population, with specialised needs concerning library services.

\subsection{Impact of remote use}

When opacs became available through the Internet for remote use, a number of studies were done focusing on the characteristics of the emerging user group and monitoring user trends to determine how remote use would impact on libraries.

A study cited by many authors ${ }^{4}$ was done in 1987 at Pennsylvania State University by Elizabeth Dow. The population surveyed were subscribers to the MUG Newsletter

\footnotetext{
${ }^{4}$ Among these are: Kalin (1991), Snelson (1993), Heller (1992), Rockman (1998).
} 
who lived in Pennsylvania. The newsletter was issued by the Computation Center at Penn State University. This method of sampling was used as it provided "a way to reach the population" (Dow 1991, 216). The author acknowledges that the choice of population has probably influenced the demographics of the study, for example one would expect that recipients of the $M U G$ Newsletter are likely to be sophisticated computer users and a computer positive group (Dow 1991). This has to be kept in mind when interpreting the findings.

1169 questionnaires were mailed out. Of the 343 returned surveys, 338 were valid. All respondents had access to $\operatorname{LIAS}^{6}$. The results discussed in the following relate only to those who dial into LIAS, which reduced the sample size to 188 or less respondents.

Dow (1991) found that for most respondents (62.7\%) the frequency of visiting the library in-house did not change after they started using LIAS from a remote computer. $29.8 \%$ used the library less frequently and $7.4 \%$ more frequently in-house.

$76 \%$ of 184 respondents felt that they were much more efficient since they has started using LIAS from a remote computer. Dial-in access is often used for quick bibliographic checks: " They dial into the library to check existence and location of material...or to check details of the bibliographic citation before they actually sally forth onto a campus with multiple library sites and crowded parking lots (Dow 1991, 220).

\footnotetext{
${ }^{5}$ Newsletter for all microcomputer user groups.

${ }^{6}$ LIAS is Penn State University Libray's Information Access System.
} 
Dow (1991) also found that respondents were using more sources, but that actual work in the library, such as reading, writing, studying and meeting with colleagues decreased by $40.6 \%$. She found that generally the population surveyed was using the library less but enjoying library research more (Dow 1991, 221).

Looking at this study it has to be kept in mind that the respondents probably have a positive attitude towards computer use and do not necessarily represent all remote users of LIAS. The results could be skewed towards the preference of using the computer instead of spending more time in the library for example to browse the shelves. The sample size (188 or less) of remote LIAS users was also fairly small to be representative for all remote LIAS users.

In 1992 Paul Heller looked at attendance and circulation statistics at the University of Norwich since remote access had been introduced and found that there was a steady increase, even though student numbers had declined. As "the only significant change in the environment of the library has been the introduction of an integrated system with remote access" (Heller 1992, 288), he concluded that remote access was the reason for increased physical library use. This conclusion has to be treated with caution as it was not derived from a research study, but was based only on the interpretation of two sets of data.

At the same time Ferl and Millsap (1992) did their often cited landmark study which looked at the remote use of the Melvyl system. ${ }^{7}$ This study was well conducted, stating clearly the research purpose, which was to study the population of remote 
users, giving background information, a short literature review, definitions, and a detailed explanation of the method used, an online questionnaire. The full questionnaire and a summary of the answers are also given. The way the questionnaire was administered is explained in detail. The large sample of 1417 completed surveys (28\% return rate) gives this study some claim to be representative.

The questionnaire asked 15 questions, which are divided in four categories: location of the user, demographics, frequency of remote and in-house library use and help and other features wanted. Responses to each question are illustrated in a separate table, which is a way of presenting the results for each question clearly and makes it easy to refer quickly to the findings of a particular question. Even though all remote users were surveyed, separate statistics for UC (University of California) users are given, which is relevant for this study. This survey yielded a wealth of statistical data concerning remote users.

Looking at the impact that remote use has on in-house library use, this survey found that, for $62 \%$ (738) of UC users surveyed, having remote access to Melvyl did not change the frequency of their visits to the UC libraries, and for those UC users whose frequency of visits did change, the number who visited less frequently is three times as large $(17.3 \% ; 222)$ as those who visited more frequently $(5.5 \% ; 71)$ (Ferl and Millsap 1992). These findings confirm Dow's (1991) findings, but contradict Heller's (1992) observation that library visits increased with remote access.

As stated by Rockman, reports on the impact of remote access on in-house library attendance have "conflicting conclusions" (Rockman 1998, 242). As most studies 
look at a particular institution or system and some have small sample sizes, it could be assumed that some studies reflect local conditions which cannot be generalised.

It is also important to note that Ferl and Millsap (1992) measured only changes to the frequency of library visits and not to the amount of time spent or the tasks performed in the library.

\subsection{Characteristics of remote users}

A number of studies look specifically at characteristics of remote users, their demographic details and their attitudes towards information technology.

\subsubsection{User groups}

Dow (1991) also looked at the demographics/characteristics of the respondents and found that there was a statistically significant relationship between age and use of a workstation: $70 \%$ of the $15-34$ year olds, $54.3 \%$ of the $35-54$ year olds and $43.4 \%$ of those aged 55 and older dial into LIAS. There was also an inverse relationship between status and workstation use: LIAS was used by $92.3 \%$ of the masters students, $80 \%$ of the doctoral students, $67.5 \%$ of the non-tenured faculty, $61.5 \%$ professional staff members and $61 \%$ tenured faculty. Within the academic disciplines, the largest user group (43\%) came from the sciences and engineering studies (Dow 1991, 217 218). As mentioned above, the method of sampling could have had an influence of these findings, although they are consistent with findings by others below. 
The results of the questionnaire administered by Ferl and Millsap (1992) previously described revealed that $55.2 \%$ of all remote users were either on campus or within five miles of a UC campus and therefore had access to the physical library. Of these $21.2 \%$ were graduate students, $14 \%$ faculty, $7.3 \%$ junior or senior and $3.5 \%$ freshmen or sophomore students. Similar results were found by other studies.

Bushallow-Wilbur, de Vinney, and Whitcomb (1996) conducted a study at three library units at the State University of New York (Buffalo). The study examined email reference questions over a period of 18 months (1993/1994). Additionally a questionnaire was sent to all who posed one or more questions during that period. This is a well conducted study, giving an informative abstract, a literature review and clearly stating its purpose ${ }^{8}$, methods and results. These are represented in easy to follow graphical formats ${ }^{9}$, which present a good overview of the findings.

As the service was newly introduced at the time of the study and not very heavily used, the overall sample was small: 114 questionnaires were returned, which was a $66 \%$ response rate (Bushallow-Wilbur et al. 1996, 362). This has to be kept in mind when interpreting the results. Of the respondents $35 \%$ were faculty, $44 \%$ graduate students and only $6 \%$ undergraduate students. (ibid., 360). The study also found that most responses (95) were sent from on-campus locations whereas 63 were sent from home or "other" locations.

\footnotetext{
${ }^{8}$ The purpose of the survey was to determine demographic information, questioners' preferences in terms of how they make queries, how the questioner became aware of the service and the reason for using the service (Bushallow-Wilbur et al. 1996, 361).

${ }^{9}$ Tables, different graphs and pie-charts were used.
} 
Ingrid Hsieh-Yee (1996), who surveyed juniors at two universities, found that $28 \%$ were using the library remotely, which she thought was not high, "considering the widespread use of computers" (Ysieh-Yee 1996, 165). The percentage of undergraduate students seems to be higher than in earlier studies mentioned above. Local conditions and a greater availability of computers could be two reasons. But in principle the findings are consistent with the above research results, which found that most undergraduates are in-library users.

Relating to Hsieh-Yee's (1996) findings that most undergraduate students are inhouse library users, Clougherty et al. (1998) also found in a comprehensive survey on undergraduate resources and services needs that "the data suggest that undergraduates prefer human contact and gravitate toward on-site use of library services and resources" (Clougherty et al. 1998, 582). This finding has no statistical value, as it was derived from undergraduates' responses to open-ended questions.

\begin{abstract}
Although not all of the findings in the above mentioned studies are statistically founded, results seem to be consistent in that undergraduates as the largest user group of the university library (Clougherty 1998) continue to represent the lowest user group of remote services.
\end{abstract}

\title{
2.2.2 Attitudes towards information technology and library use
}

\author{
Vander Meer, Poole, and Van Valey $(1996,1997)$ examined the relationship between \\ computer use and library use. The authors surveyed faculty and students of the \\ Western Michigan University in two different surveys. They created an "index of
}


library use" for both user groups, distinguishing between frequent library users and infrequent library users. These groups were then compared to determine if significant differences exist between them in relation to usage of computers (Vander Meer et al. 1997, 5). Sample sizes for both groups were relatively large: 314 (42.3\% response rate) for faculty and 1273 (26.5\% response rate) for students, which gives the studies some credit.

In both cases the authors found that frequent library users are also heavier users of different computer applications, such as word processing and e-mail. They use the computer more often and have a more positive attitude towards using computers for their work.

Although the findings cannot establish that "there is a causal connection between computer use and library use" (Vander Meer et al. 1997, 9), there were consistent findings that "computer skills are clearly associated with high levels of library use" (Vander Meer et al. 1996, 343).

Because the student body is changing with increasing computer training in schools, younger students entering university can be expected to be more computer literate (ibid. 339). A large survey (mailed questionnaire, 1424 responses) done by Berger and Hines (1994) at the Duke University Library found that there is a growing acceptability of computerization and that undergraduates are most open to computerization, whereas faculty is least computer orientated (Berger and Hines 1994). 
The findings of these three studies are important for this study as they can be used to determine if more familiarity and a more positive attitude towards using computers has increased students' acceptance of and readiness in using Internet-based library services. Vander Meer et al. (1996) also suggest that further research is needed on the effect of the Internet on students' library use.

Two other studies done on the adaptation of technology should be mentioned here. Liebscher et al. (1997) surveyed science and engineering faculty of six small universities. ${ }^{10}$ Data was gathered by a mail questionnaire (returned by $216,59 \%$ ) and follow-up site visits. The respondents were classified in three groups: users (65\%), non-users $31 \%$ and non-adopters (4\%) of the campus networks. The authors assume that the majority of the $41 \%$ who did not respond to the survey were probably nonusers because there were no easily accessible network connections. This has to be kept in mind when analysing the data.

The main finding of this study was that, given a network connection which is perceived as easily accessible, the majority of science and engineering faculty will readily adopt the service and make use of it (Liebscher et al. 1997, 505). Findings show, for example, that remote databases were accessed by $65.2 \%$. Many of the faculty members also mentioned that easy access to the Internet for students was increasingly important (ibid., 506).

A study by Starkweather and Wallin (1999) examined faculty's attitudes regarding computer-based information resources through a series of focus group sessions and

\footnotetext{
${ }^{10}$ Small universities are more dependent on network access as limited resources are available locally.
} 
personal interviews. This is an interesting approach as two qualitative research methods are used (and no representative sample of faculty) to gain a better understanding of the psychology of user acceptance. To do this the authors grouped participants into three adopter categories of technology: the early adopters, early majority and late majority ${ }^{11}$. They found that early adopters and early majority are also more likely to encourage students to use websites and electronic resources in the library (Starkweather and Wallin 1999, 9). The authors stress that librarians must be aware of the differences among teaching staff regarding their attitude towards information technology.

The findings of both these studies are relevant to this study as it can be assumed that the attitude of teaching staff towards information technology and therefore towards electronic library services will affect students' adaptation of these services. If teaching staff have adopted these services, they will promote them to students.

\subsection{User needs, expectations and satisfaction with remote library services}

Many studies which look at user needs, expectations and/or satisfaction with library services in general also examine remote Internet-based library services as part of the library's services and resources offered. Recurring themes concerning remote library services are convenience, saving time, 24 hour access, importance of accessibility, need for different formats of help/instruction, need for marketing of services to increase awareness of what is available and generally high expectations of remote services.

\footnotetext{
${ }^{11}$ Details about the characteristics of each adopter category are given by the authors in the appendix of the article.
} 


\subsubsection{Awareness}

An often cited study by Adams and Bonk (1995) was conducted to assess user needs and expectations rather than user satisfaction with electronic services. ${ }^{12}$

Questionnaires asking about faculty access to, use of, and expectations related to electronic technologies and information services were distributed to all core teaching faculty and selected administrators and professionals at all four campuses of the SUNY University Center. The questionnaire also allowed for comments. 1007 questionnaires were returned, which was a $27 \%$ return rate. Results of this study are clearly represented in separate tables. A main finding of this survey was that there was a lack of awareness of remote library services and resources available. $61.5 \%$ of respondents reported a lack of information on databases as the "main obstacle to use electronic resources" (Adams and Bonk 1995, 126).

It has to be kept in mind that this survey was conducted in 1992, when remote services ${ }^{13}$ were first being offered at SUNY, and not everyone had easy access to the campus network. Although these factors could account for an increased lack of awareness, many other authors ${ }^{14}$ also mention that users often lack awareness of remote services being offered. In a much more recent study Weingart and Anderson (2000) investigated awareness of electronic databases among faculty. A questionnaire

\footnotetext{
${ }^{12}$ In a study of user surveys Schlichter and Pemberton (1992) found that surveys measuring satisfaction with library services often have "contradictory or no significant results" (Schlichter and Pemberton 1992,258 ) as users can report high satisfaction with a service or resource at the same time as the survey shows a low level of awareness or use of this service (ibid., 259).

${ }^{13}$ These were telnet access to the opac and to some journal indexes as well as access to the Internet and email.
} 
was distributed and returned by $49.8 \%$ (426 respondents). The authors found that there was a "strong response bias in favour of those with greater electronic experience" (Weingart and Anderson 2000, 128). It has to be kept in mind that this could always be a problem when distributing questionnaires to all.

A table illustrates awareness and use of remote database access and the library's homepage. The authors found that $67.6 \%$ were aware of remote access to databases, which is quite high, but only $53.6 \%$ had used them, whereas $20.2 \%$ were not aware of remote database access and $12.1 \%$ were unsure. Slightly lower percentages were found for knowledge about and accessing the library's homepage. Considering there was a response bias towards the more computer experienced, and the sample was therefore not representative for the faculty, the real figures would most likely be even lower.

In a large survey (823 graduate students and 282 faculty), Patricia Maughan (1999) examined faculty's and graduate students' satisfaction with library services at Berkeley UC. The author also found that many of the respondents lacked awareness and reported "insufficient experience" with many of the library's services and resources. For example the library's website is still not known by many faculty as a library resource as "very few reported exploring the library's website" (Maughan 1999, 358).

\footnotetext{
${ }^{14}$ For example: Starkweather and Wallin (1999), Clougherty et al. (1998), Bushallow-Wilbur (1996), Maughan (1999)
} 


\subsubsection{Training needs}

Maughan (1999) sees a lack of exposure to training as one of the reasons for lack of awareness of what is available. Many other authors ${ }^{15}$ identify a need for training delivered in different formats. Adams and Bonk (1995) found that most preferred small group class/workshops, printed manuals and online tutorials. Fairly similar results were found by McCarthy, Krausse, and Little (1997), who examined student satisfaction with CD-ROM databases. Students most preferred personal assistance from staff, closely followed by hands-on workshops and online help screens.

Different ways of delivering training have to be offered in order to suit different user needs. It can be assumed that many of the remote users also increasingly want training through the Internet. A study done by Rhodes and Chelin (2000) investigated internetbased user education in 68 university libraries. They found that $10 \%$ of user education is currently delivered through the Internet. The authors predict that this will increase.

\subsubsection{Accessibility}

Lack of access is often mentioned as a barrier for remote use of electronic information services. Adams and Bonk (1995) found that in 1992 between $25 \%$ and $30 \%$ of faculty lacked either hardware or network connections. This could also be a reason why undergraduates were found to have the lowest use of remote library services.

\footnotetext{
${ }^{15}$ Adams and Bonk (1995), Weingart and Anderson (2000), Ferl and Millsap (1992), Millsap and Ferl (1993).
} 
Snelson (1993) reports that recent studies point to a connection between accessibility and use, as the "volume of use is directly related to the convenient placement of the terminal in the workplace" (Snelson 1993, 73). Convenience, saving time and 24 hour access are mentioned in many studies ${ }^{16}$ as major reasons for using remote library services and resources.

\footnotetext{
${ }^{16}$ Starkweather and Wallin (1999), Bushallow-Wilbur et al. (1996), Kalin (1991)
} 


\section{Design of the study}

\subsection{Research setting}

The study was conducted at the School of Education (SOE) of the University of Waikato. This is currently the second largest school of Waikato University. The school mainly offers a variety of programmes for teacher training.

The following describe unique features of the school, which reflect local conditions of the study and influenced some of the findings:

- The SOE is the only school of the University of Waikato which has a branch library located within the school. The Education Library is the only branch library of the wider Waikato University Library. This has historical reasons: until 1991 the SOE was an independent Teacher Training College.

- As the main business of the School is teacher training, few students undertake postgraduate studies, eg. masters or honours degrees.

- There are teacher training programmes for graduate students. These students are in their fourth (or more) year of study and are grouped as graduates in this survey. It has to be kept in mind that the needs of these graduate students may differ from information needs of students doing post-graduate studies

- Teacher training is resource-based. Students are required to take library resources out on practicum and frequently into classes for presentations, lesson planning etc. Consequently there is a high need for students to use the Library in-house. 
These unique features and local conditions have to be kept in mind, when interpreting the data and drawing conclusions as results cannot automatically be generalised.

The main reasons for conducting the survey in the SOE were that:

- Access to classes was easy for the researcher to organise within one school

- Conducting the survey at one school offered the opportunity for the school to be thoroughly investigated (see sampling method below)

- This survey could be used as a pilot study and could be conducted at other schools of the University at a later date.

\subsection{Sample design}

The population surveyed were on-campus students of the School of Education, University of Waikato, who are enrolled in one of the main teacher training programmes. The total number of students in this group is $1120^{17}$.

The sample frame was designed first by selecting the main teacher training programmes and then by selecting compulsory classes of each level (year) within each programme.

Below is a list of the programmes selected, including numbers of currently enrolled on-campus students:

\footnotetext{
${ }^{17}$ Figures are from April 2001
} 
- BTchg- Early Childhood, a three-year programme for early childhood education, 138 students

- BTchg-Primary, a three-year primary teacher education programme, 626 students

- BTchg-Secondary Cojoint, a four+-year cojoint undergraduate programme for students who undertake subject studies and professional education studies (for secondary teacher education) concurrently, 121 students

- Ropu Rumaki, a three-year primary teacher education programme where students complete a substantial proportion of their programme through the medium of the Maaori language, 59 students

- GradDipT-Primary- a one-year intensive primary teacher education programme for graduates with Bachelor or higher degrees, 78 students

- GradDipT-Secondary- a one-year intensive secondary teacher education programme for graduates with Bachelor degrees or higher, 85 students

- BTchg (Hons)- a one-year honours degree, primarily for graduates of the Bachelor of Teaching degree, 13 students

(from: Undergraduate studies handbook 2001; all figures given from April 2001)

Altogether 11 classes were visited which covered all programmes at each level. Some classes combined students from different programmes eg. BTchg Primary and Ropu Rumaki were surveyed in the same classes. Compulsory classes were selected to capture as many students as possible from each programme and level.

The sample was stratified by programme and classes (levels) and selection was random within the classes as participation was voluntary. 
Possible sampling bias:

- Accessibility bias: students who did not attend class that day were not surveyed.

In addition, students who were not enrolled in one of the selected classes were not included in the survey

- Non-response bias: a small number of students refused to participate

\subsection{Data collection}

Prior to data collection, ethical approval for the study was obtained from the Ethics committee of Victoria University of Wellington and the chairperson of the Ethics committee of the School of Education was informed about the survey. All respondents were guaranteed anonymity. Questionnaires were not marked in any way to identify respondents. This was explicitly mentioned in the cover letter and in class when the questionnaires were introduced. It was also mentioned that participation was voluntary.

Lecturers were then contacted to arrange a time during the first two weeks of April (see 1.6; Delimitations) when the classes could be visited to conduct the survey. All lecturers gave some time for introducing and distributing the questionnaires. Except for one class, the surveys could be filled out immediately and collected. Most surveys were done at the beginning of the class, except for one, which was done at the end. Questionnaires were handed out to everybody present in the classes who wanted to participate. 
The fact that the lecturers made some time available to personally introduce the researcher and questionnaire and to fill out the form helped to achieve a very high return rate. Of the 636 questionnaires handed out, 618 (97.2\%) were returned and 558 $(87.7 \%)$ could be used for the survey. 60 questionnaires were invalid for the following reasons:

- Respondent was not enrolled in one of the teacher training programmes (12 questionnaires)

- The survey form was not completed and resulted in too much missing data (14 questionnaires)

- Information given on the survey form was conflicting and could not be interpreted by the researcher. For example a common mistake made by respondents was that

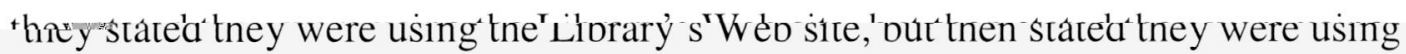
none of the services offered by remote access. Most likely general Internet use was confused with using the Library's Internet-based services and resources (34 questionnaires).

\subsection{Survey instrument}

Data were collected by distributing an anonymous questionnaire. The questionnaire and coverletter used as survey instrument can be found in Appendix I. It was designed to gather the data needed for statistical analysis to answer the research problem (see 1.4), research questions and to test the hypotheses (see 1.5).

Some questions on training needs $(\mathrm{Q}, \mathrm{R})$ and a space for additional comments (U) were included to gather additional information of interest to the Library. 
The questionnaire consists of 20 questions and took 3-5 minutes to complete. The survey instrument aims for a clear and varied layout. For example, the order of choices was varied in questions $\mathrm{J}, \mathrm{K}$ to discourage automatic responses.

The questionnaire consists of five parts:

I. Questions related to the characteristics (demographics) of students ( A, B, C, $\mathrm{D}, \mathrm{S}, \mathrm{T})$

II. Questions related to access to the Internet and awareness of the Library's Web site $(\mathrm{E}, \mathrm{F}, \mathrm{G}, \mathrm{I})$

III. Questions related to in-house and remote library use-patterns ( J, K, L, M)

IV. Questions related to the possible impact that remote use of the Library has on the in-house use of the Library ( N, O, P)

V. Questions related to training needs and to collect additional comments (Q, R, U)

Question N was adapted from Ferl and Millsap's (1992) questionnaire.

The questionnaire uses both closed and open questions. Most questions are closed (A, D, E, I, L, M, N, O, P, Q, S, T). Questions B, C, F, G, J, K, R give one option each, which allows for additional choices and more detailed comments. The last question (U) is completely open and designed to collect some additional information and qualitative comments. 
Questions were kept as short as possible. Terms were chosen which are widely understood among the student population. For this reason local terminology was used, for example " desk copy". One category (year of study) was initially quite detailed to collect as accurate information as possible, but was later collapsed into four categories ( year one, two, three and four+) to ensure that each category had a sufficient number of cases for statistical analysis.

Questions relating to the characteristics (demographics) of students (part I) were placed at both the beginning and the end of the questionnaire because they are easy to answer and might motivate students to complete the questionnaire.

There are four points of branching to direct certain respondents. These can be found in questions $\mathrm{E}, \mathrm{G}, \mathrm{Q}$ and before question N. Branching is indicated by arrows to guide respondents.

\subsection{Pre-test}

The survey instrument was pre-tested with a diverse group of student assistants working in both the Education and Central University Library. This group was chosen because student assistants are easy to contact. They are a diverse group ranging from first year to graduate students, international students, Maaori students and students enrolled in different schools. Their knowledge of the Library's resources and services is also wide ranging. 
46 questionnaires were distributed and 30 questionnaires were returned. Of these:

- 20 were filled out correctly

- two were not completed

- two misunderstood a question

- three had some missing data (related to different questions)

- three misunderstood one question and had missing data

None of the respondents made critical comments about terminology used or difficulty of following the questionnaire.

Missing data related to different questions and no conclusions could be drawn about the reasons for omitting the data.

Question G: Have you used the University of Waikato Library's resources/services available from the Library's Web site? was clearly most often misunderstood.

Presumably students thought the question relates to Internet use in general (for finding information for assignments). The question was amended ${ }^{18}$ by adding an example and the Web site address for clarification.

Even though these additions were made, this question was also most often misunderstood in the survey and would need improvement if the questionnaire was used again. To aid further clarification question K: Please state which library services/resources you use through the Library's Web site from outside the Library

\footnotetext{
${ }^{18}$ G. Have you used the University of Waikato Library's resources/services (for example the catalogue) through the Library's Web site (http://www.waikato.ac.nz/library/) from outside the Library?
} 
could immediately follow question $\mathrm{G}$. If the researcher is able to address the respondents, this question could be explained.

Finally, the pre-test highlighted that some degree of personal contact between the researcher and respondent to explain the rationale behind the questionnaire increased the return rate. There was a clear difference between questionnaires handed out by the researcher personally and those left to be distributed by others. This was also reflected in the high return rate of the survey.

\section{Treatment of the data}

\subsection{Procedure}

After each class visit, questionnaires were checked and given a number and ID code eg. E1 for Early Childhood, year 1. Questionnaires were sorted by programme and level. Each questionnaire was then entered into a spreadsheet using the statistical programme SPSS ${ }^{19}$. This programme was used because it can cope with missing data and large spreadsheets.

Each questionnaire was evaluated as it was entered into the spreadsheet. 60 questionnaires were rejected and a total of 558 questionnaires could be used for data analysis (see 3.3).

\footnotetext{
${ }^{19}$ SPSS, statistical programme for social sciences, version 10.5 .
} 


\subsection{Coding}

Each question of the questionnaire was coded from left to right, for example, question F was coded as follows:

home $=1$, computer lab on campus $=2$, library $=3$, work $=4$, other $=5$.

During initial data input into the spreadsheet, questionnaires which needed to be postcoded were marked and sorted out. Answers given in the "other" categories were noted down in order to be collated later. All additional comments made in question $U$ were also noted down.

Only questions $\mathrm{F}$ and $\mathrm{G}$ needed post-coding:

- Two new variables were created for question F: Where do you access the Internet friends $=5$ and public places $=6$. The original " other " variable was eliminated.

- One new variable was created for question G: Reasons given why the Web site is not used. $22.4 \%$ of all respondents $(54.0 \%$ of students who do not use the Library's Web site and answered "no" to question G) gave a variety of reasons. These were coded as follows: no knowledge of/don't know=1; no need=2; no access $=3$; rather go to library $=4$; other $=5$.

Basic frequency tables (case summaries) were then produced to gain an overview of the data collected and to locate irregularities such as errors in data entry. 
As mentioned before question B: Please state your year of study was collapsed into 4 categories: Year 1, 2, 3, 4+ to ensure that all categories are large enough to compare groups and perform statistical tests, such as chi-square, which needs a minimum of 5 respondents per category.

\subsection{Missing data}

Most missing data (non-responses to questions) were found in question L: How often do you use library services in the library and from outside the library (33/22) and question M: On average how much time do you spend using the library's services in the library and from outside the library (37/39). It is not clear if some respondents did not understand how they were meant to answer the questions or if they found these questions hard to answer. It can be assumed that both were the case.

To keep the data authentic, missing values were not replaced by a mean value or other method and appear in the statistical output files as "missing". The value used for missing data was "99".

\subsection{Procedures used to analyse data}

Data gathered through the questionnaire are nominal and ordinal. The following questions collect nominal data: A, B, C, D, E, F, G, I, J, K, Q, R, S, T. Ordinal data are collected by questions $\mathrm{L}, \mathrm{M}, \mathrm{N}, \mathrm{O}, \mathrm{P}$. Question $\mathrm{U}$ is not designed to collect data for statistical purposes. 
No continuous data were collected in the survey. Continuous data, such as age, were coded into categories, for example 16-21, 22-27 etc.

The following procedures were used to analyse the data:

- Frequency tables and bar charts were used to illustrate the number of responses (frequencies) for each question (variable)

- Basic tables were used to illustrate frequency and percentages for two or more variables (for example: gender and Internet use)

- As most data collected were categorical, cross tabulation were used to illustrate the relationship between two or more categorical variables in tabular or graphical form.

- Multiple response tables were created for questions where students could give more than one answer, for example: Where do you access the Internet? Please tick all boxes applicable.

- To enhance the presentation of data and for some statistical analyses, sometimes categories were re-coded (collapsed) into fewer categories, for example the age categories. Instances of this are noted in the text.

- For some analyses of data the select cases function was used. For example, in any analyses concerning remote users only, these cases were selected (see 5.3).

- Chi-square tests for independence were used to determine if two categorical variables, for example status and remote use of the Library, are related. As generally accepted by social scientists, the result of a chi-square test was considered statistically significant in this study if the significance value (p) was smaller than 05 . This means that there is a $5 \%$ or less chance that the outcome 
occurred by chance and that there is a $95 \%$ chance that the two variables tested are not independent of each other.

A chi-square test could only be performed if the expected frequencies in the crosstabulation table were 5 or higher.

Slight variations in total numbers $(\mathrm{N})$ presented in the tables are due to missing data as some respondents failed to answer a question. Where a substantial number of answers were missing to a question, especially to questions $\mathrm{L}$ and $\mathrm{M}$, this is mentioned in the text and the total number of respondents $(\mathrm{N})$ is given in the text and/or in the caption of the table. 


\section{Results}

In the following the results of the survey are described and presented in relation to the statement of the problem (see 1.4) and the research questions (see 1.5). Initially the population $(\mathrm{N}=1120)$ and the sample $(\mathrm{N}=558)$ are compared to determine how much the demographic features of the sample differs from the population.

\subsection{Population and sample}

The following variables describe the demographic features: gender, age, status (undergraduate or graduate), year of study, programme of study and part-time or fulltime study. A summary of the School of Education statistics for the whole population can be found in appendix 2 .

Gender

In the sample population there were $79.4 \%$ females and $19.9 \%$ males. $0.7 \%$ of the respondents did not provide the information. In comparison the total population has a proportion of $77.5 \%$ females and $22.3 \%$ males. This means that in the sample male respondents are slightly under-represented.

Age

In the sample $46.2 \%$ of the students surveyed were in the youngest age category (1621 years old), $22.2 \%$ were $22-27$ years old, $11.9 \%$ were $28-34$ years old, $16.2 \%$ were 35-44 years old and 3.4\%were $45+$ years old. In comparison the total population shows the following age distribution: $36.5 \%$ were $16-21,22.7 \%$ were $22-27,14.3 \%$ 
were $28-34,20.4 \%$ were $35-44$ and $6.1 \%$ were $45+$ years old. In the sample the youngest age group is over-represented by nearly $10 \%$ and all other age groups are under-represented.

Status

$77.4 \%$ of the respondents to the survey were undergraduate and $22.6 \%$ were graduate students. The total population consists of $84.3 \%$ undergraduates and $15.7 \%$ graduates. This means that in the sample graduate students are over- represented.

Year of study

In the sample first year students represented the largest group of respondents (30.8\%). $22.8 \%$ were second year students and $21.5 \%$ third year students. $24.7 \%$ of the students were in their fourth year or higher.

In comparison the total population has a more even distribution of year one to three students: $26.8 \%$ are year one students, $27.3 \%$ year two and $30.2 \%$ year three students. $15.7 \%$ are in their fourth year or higher. In the sample, year one and year four + students are over-represented, and year two and year three in particular are underrepresented.

Programme of study

Seven programmes were identified as main teacher education programmes offered by the School of Education (see 3.2). There were no respondents for year two Ropu Rumaki students. 
Of the undergraduate programmes, the largest is the three year programme for primary teachers (BTchg-Primary) followed by BTchg-Early Childhood, BTchgSecondary Cojoint and the Ropu Rumaki programme.

In the sample $50.2 \%$ of the respondents were enrolled in BTchg-Primary, $16.1 \%$ in BTchg-Early Childhood, $9.1 \%$ in BTchg-Secondary Cojoint and 2.3\% in the Ropu Rumaki programme.

In the whole population $55.9 \%$ of the students are enrolled in the BTchg-Primary programme, $12.3 \%$ in the BTchg-Early Childhood, $10.8 \%$ in BTchg-Secondary Cojoint and $5.3 \%$ in the Ropu Rumaki programme.

Three graduate programmes were included in this study. The one-year graduate programmes for primary and for secondary teacher education are similar in size. The group of BTchg-Hons students is much smaller.

In the sample $9 \%$ of all respondents were enrolled in the GradDipT-Primary programme and $11.5 \%$ in the GradDipT-Secondary programme. $1.8 \%$ were BTchgHons students. In comparison the whole population has 7\% GradDipT- Primary and 7.6\% GradDipT-Secondary students. $1.2 \%$ are BTchg-Hons. students.

Because graduate students were found before to be over-represented, their programmes are also over-represented in this study. Of the undergraduate programmes, BTchg-Primary, BTchg-Cojoint and Ropu Rumaki students are underrepresented and BTchg-Early Childhood students are over-represented. 
Part-time/full-time study

Of the students surveyed, $97.7 \%$ were full-time students and $2.3 \%$ part-time students.

In comparison, $90.1 \%$ of the total population are full-time and $9.9 \%$ are part-time students. Part-time students in this study are under-represented.

\subsection{Internet access and use of the Library's Web site}

The majority of all respondents $83.1 \%$ (463) use the Internet. $16.9 \%(94)$ are nonusers. Table 1 below shows that over two-thirds of undergraduate students $(79.8 \%$; $344)$ and nearly all graduate students $(94.4 \% ; 119)$ use the Internet.

Of all students surveyed who use the Internet (N=463), 74.3\% (344) are undergraduate students and $25.7 \%$ (119) are graduate students.

\begin{tabular}{|c|c|c|c|c|c|c|c|c|c|}
\hline & \multicolumn{6}{|c|}{ Current status of respondent } & \multicolumn{3}{|c|}{ Table Total } \\
\hline & \multicolumn{3}{|c|}{ Undergraduate } & \multicolumn{3}{|c|}{ Graduate } & & & \\
\hline & Count & Row \% & Col \% & Count & Row \% & $\mathrm{Col} \%$ & Count & Row \% & $\mathrm{Col} \%$ \\
\hline Internet yes & 344 & $74.3 \%$ & $79.8 \%$ & 119 & $25.7 \%$ & $94.4 \%$ & 463 & $100.0 \%$ & $83.1 \%$ \\
\hline use & 87 & $92.6 \%$ & $20.2 \%$ & 7 & $7.4 \%$ & $5.6 \%$ & 94 & $100.0 \%$ & $16.9 \%$ \\
\hline Table Total & 432 & $77.4 \%$ & $100.0 \%$ & 126 & $22.6 \%$ & $100.0 \%$ & 558 & $100.0 \%$ & $100.0 \%$ \\
\hline
\end{tabular}

Table 1: Use of the Internet by undergraduate and graduate students

\section{Research question (RQ) 1: Where do students gain access to the Internet?}

A summary of the responses is given in Table 2 below. 
The Internet is most often accessed from home by slightly over three-quarters $77.2 \%$ (356) of the respondents. "Home" is defined here as the place where the student lives, and includes answers such as "College Hall" and "flat". Around one-third of the respondents reported accessing the Internet in computer labs on campus $(36.4 \% ; 168)$ and/or in the library $(33.8 \% ; 156)$. Only small percentages of respondents use the Internet at work $(3.9 \% ; 18)$, at a friend's place $(3.5 \% ; 16)$ and in public places such as cyber cafes $(1.1 \% ; 5)$.

Percentages for undergraduate and graduate students do not vary much.

\begin{tabular}{|c|c|c|c|c|c|c|c|}
\hline & & \multicolumn{4}{|c|}{ Current status of respondent } & \multicolumn{2}{|c|}{ Total } \\
\hline & & \multicolumn{2}{|c|}{ Undergraduate } & \multicolumn{2}{|c|}{ Graduate } & \multirow[b]{2}{*}{ Count } & \multirow[b]{2}{*}{ Column \% } \\
\hline & & Count & Column \% & Count & Column \% & & \\
\hline \multirow{6}{*}{$\begin{array}{l}\text { Where the } \\
\text { Internet is } \\
\text { accessed }\end{array}$} & Home & 271 & 78.8 & 85 & 72.6 & 356 & 77.2 \\
\hline & Computer lab on cam & 123 & 35.8 & 45 & 38.5 & 168 & 36.4 \\
\hline & Library & 122 & 35.5 & 34 & 29.1 & 156 & 33.8 \\
\hline & Work & 13 & 3.8 & 5 & 4.3 & 18 & 3.9 \\
\hline & Friends & 14 & 4.1 & 2 & 1.7 & 16 & 3.5 \\
\hline & Public places & 2 & .6 & 3 & 2.6 & 5 & 1.1 \\
\hline Total & & 344 & 100.0 & 117 & 100.0 & 461 & 100.0 \\
\hline
\end{tabular}

Table 2: Where the Internet is accessed by undergraduate and graduate students

\section{RQ 2: What is the number (percentage) of undergraduate and graduate on-} campus students using remote access to the Library?

Of all respondents to the survey $(\mathrm{N}=558), 41.4 \%$ (231) use the Library's resources and services through the Library's Web site by remote access and 58.6\% (327) do not use the Library by remote access. 
The study found that a higher percentage of graduate students use the Library by remote access (54\%) compared to $37.7 \%$ of the undergraduate students surveyed.

\begin{tabular}{|l|r|r|r|r|r|r|}
\hline & \multicolumn{3}{|c|}{ Current status of respondent } & \multicolumn{2}{c|}{ Group Total } \\
\cline { 3 - 6 } & \multicolumn{2}{|c|}{ Undergraduate } & \multicolumn{2}{c|}{ Graduate } & & \\
\cline { 2 - 7 } & \multicolumn{1}{|c|}{ Count } & \multicolumn{1}{|c|}{ Col \% } & Count & \multicolumn{1}{c|}{ Col \% } & Count & \multicolumn{1}{c|}{ Col \% } \\
\hline Remote use of yes & 163 & $37.7 \%$ & 68 & $54.0 \%$ & 231 & $41.4 \%$ \\
the Library no & 269 & $62.3 \%$ & 58 & $46.0 \%$ & 327 & $58.6 \%$ \\
Group Total & 432 & $100.0 \%$ & 126 & $100.0 \%$ & 558 & $100.0 \%$ \\
\hline
\end{tabular}

Table 3: Students' use of the Library's Web site by remote access by status

\section{RQ 3: Are students aware of the Library's Web site?}

As shown in Table 3, more than half of all students surveyed do not use the Library's Web site. Students in this group who said they use the Internet, but not the Library by remote access $(\mathrm{N}=228)$ were asked to state reason(s) why they have not used the Library by remote access. 53.9\% (123) gave a variety of reasons (see Chart 1 below).

Just under one-third of the respondents $28.5 \%$ (35) stated that they had no knowledge of the web site and/or did not know how to use it. This was the second most frequently stated reason for not using the Library by remote access.

The most frequently mentioned reason was "no need", given by $39 \%$ (48) of the respondents. A smaller number 5.7\% (7) stated that they "rather go to the library". $15.4 \%$ (19) said they have no Internet access. $11.4 \%$ (14) stated a variety of other reasons, such as "don't like Internet", "difficult to use" and "no time". 


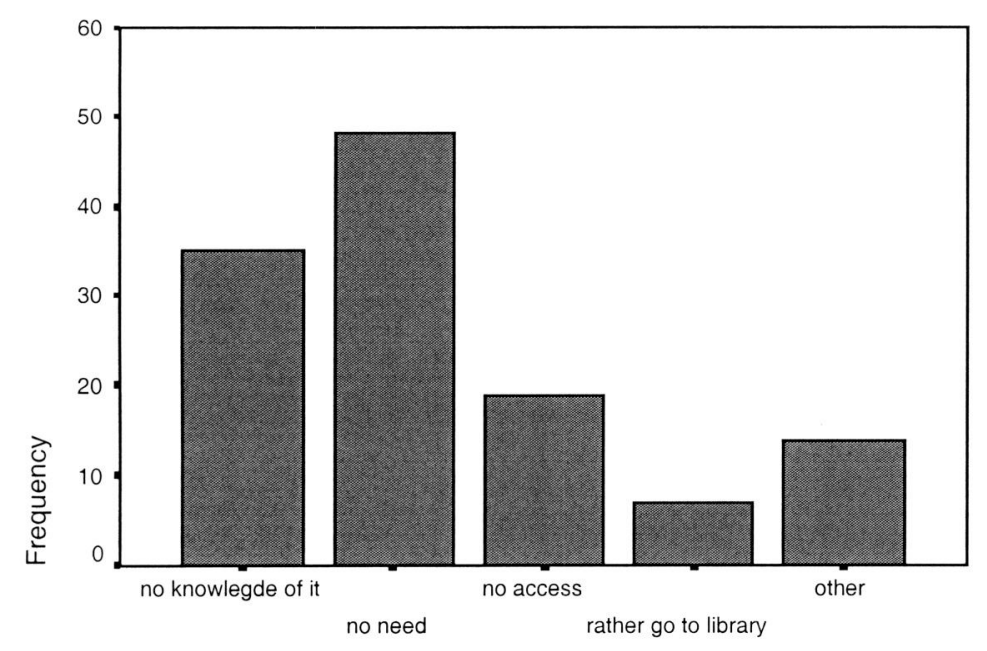

Chart 1: Reasons given why the Library's Web site is not used $\mathrm{N}=123$

\subsubsection{Length of Web site use}

Students who use the Library by remote access were asked how long they have been using the Library's Web site. For the presentation of the results the first two categories new user and 1-3 months have been collapsed into one category new user, which implies that the student has been using the Web site for up to three months, ie since the beginning of semester A.

Chart 2 below shows the distribution of respondents stating how long they have been using the Library's Web site. More than half $(54 \% ; 122)$ are new users, who have been using the Library by remote access for up to three months. $28.3 \%$ (64) have been using the Library's Web site for more than a year and 17.7\% (40) have used the Web site for between three months and one year. 


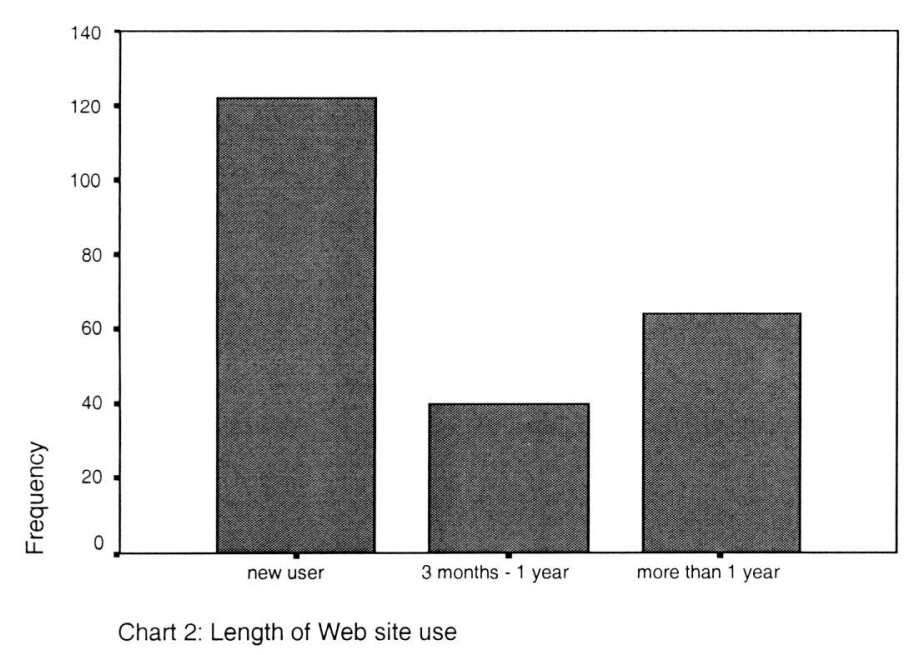

\title{
5.3 Characteristics of students who use the Library by remote access
}

\author{
In the following the data collected are analysed to determine the various \\ characteristics of on-campus students who use the Library by remote access through \\ the Web site. These are gender, age, status, year of study, programme, part-time or \\ full-time study, length of Web site use and Web site use from home.
}

Charts displayed below in each category show the number of students who use the Library's Web site in comparison to those students who use the Internet but not the Library by remote access and those who do not use the Internet at all. The middle column indicates the Library's Web site use in each chart.
Charts are followed by tables which further analyse some characteristics of the remote users group.

RQ 4: What are the various characteristics of the students who use the Library by remote access? 


\subsubsection{Gender and Web site use}

Chart 3 below shows the distribution by gender of students who use the Library's Web site by remote access.

Of all female respondents, the largest group use the Internet but not the Library's Web site $(42.7 \% ; 189)$. Over one-third $(38.1 \% ; 169)$ use the Library by remote access and nearly one-fifth $(19.2 \% ; 85)$ do not use the Internet.

Just over half of all male respondents $(53.2 \% ; 59)$ use the Library's Web site, over one-third $(35.1 \% ; 39)$ use the Internet, but not the Library by remote access and $11.7 \%$ (13) do not use the Internet.

A chi-square test for independence found a statistically significant difference between male and female respondents $(\mathrm{p}=.012)$ in their use of the Internet and the Library by remote access. 


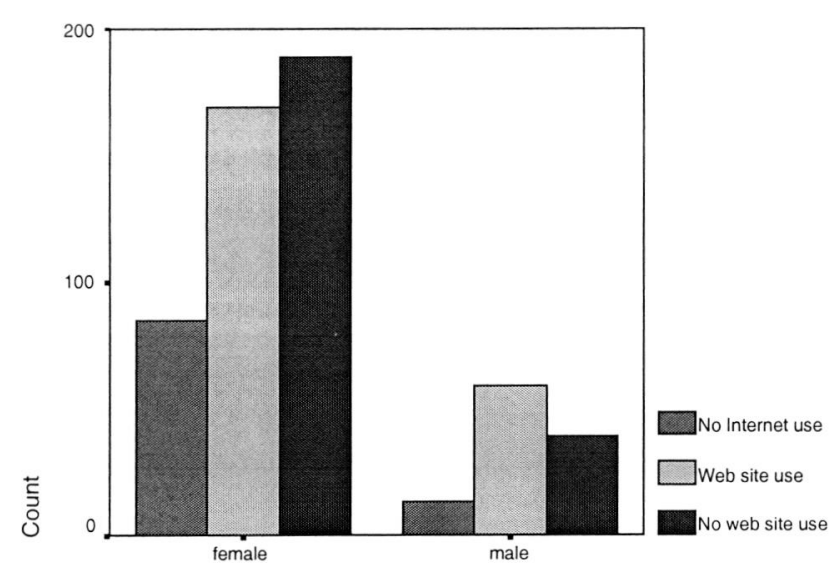

Chart 3: Web site use by gender

Table 4 below summarizes some characteristics by gender of those who use the Library by remote access.

In the sample population, $79.4 \%$ of students are female and $19.9 \%$ are male (see 5.1 ). By comparing row $\%$ in Table 4 , areas in which male and female students of the remote user group $(\mathrm{N}=231)$ are over- or under-represented compared to the distribution of gender in the sample $(\mathrm{N}=558)$ can be identified.

More than twice $(41.8 \%)$ as many male remote Library users are graduate students compared to the gender distribution in the whole sample.

Within the age categories a higher percentage of female students $(90.5 \%)$ can be found in the 35-44 age range and higher percentages of male students are in the 22-27 (38\%), $28-34(44.7 \%)$ and $45+(33.3 \%)$ age ranges compared to the sample. 
Nearly all students enrolled in BTchg-Early Childhood, Ropu Rumaki and BTchgHons are female. Higher percentages of male students can be found in the BTchgSecondary Cojoint and GradDipT-Primary and Secondary programmes.

Year 3 has a high percentage of female students (91.4\%) and year 4+ a high proportion of male students $(41.7 \%)$.

Just over half of both male and female remote users are new users of the Library's Web site and twice as many male students have been using the Libray by remote access for more than a year. A higher percentage of female students can be found in the 3 month -1 year category.

9\% more female remote Library users have Internet access at home.

\begin{tabular}{|c|c|c|c|c|c|c|c|}
\hline & & \multicolumn{6}{|c|}{ Gender } \\
\hline & & \multicolumn{3}{|c|}{ Female } & \multicolumn{3}{|c|}{ Male } \\
\hline & & Count & $\begin{array}{c}\text { Row } \\
\%\end{array}$ & $\mathrm{Col} \%$ & Count & $\begin{array}{c}\text { Row } \\
\%\end{array}$ & $\mathrm{Col} \%$ \\
\hline \multirow[t]{2}{*}{ Status } & Undergraduate & 130 & $80.7 \%$ & $76.9 \%$ & 31 & $19.3 \%$ & $52.5 \%$ \\
\hline & Graduate & 39 & $58.2 \%$ & $23.1 \%$ & 28 & $41.8 \%$ & $47.5 \%$ \\
\hline \multirow[t]{5}{*}{ Age category } & $16-21$ & 72 & $81.8 \%$ & $42.9 \%$ & 16 & $18.2 \%$ & $27.1 \%$ \\
\hline & $22-27$ & 31 & $62.0 \%$ & $18.5 \%$ & 19 & $38.0 \%$ & $32.2 \%$ \\
\hline & $28-34$ & 21 & $55.3 \%$ & $12.5 \%$ & 17 & $44.7 \%$ & $28.8 \%$ \\
\hline & $35-44$ & 38 & $90.5 \%$ & $22.6 \%$ & 4 & $9.5 \%$ & $6.8 \%$ \\
\hline & $45+$ & 6 & $66.7 \%$ & $3.6 \%$ & 3 & $33.3 \%$ & $5.1 \%$ \\
\hline \multirow[t]{7}{*}{ Programme } & $\begin{array}{l}\text { BTchg-Early } \\
\text { Childhood }\end{array}$ & 26 & $96.3 \%$ & $15.4 \%$ & 1 & $3.7 \%$ & $1.7 \%$ \\
\hline & BTchg-Primary & 83 & $82.2 \%$ & $49.1 \%$ & 18 & $17.8 \%$ & $30.5 \%$ \\
\hline & $\begin{array}{l}\text { BTchg Secondary } \\
\text { Cojoint }\end{array}$ & 16 & $57.1 \%$ & $9.5 \%$ & 12 & $42.9 \%$ & $20.3 \%$ \\
\hline & Ropu Rumaki & 5 & $100 \%$ & $3.0 \%$ & & & \\
\hline & Grad DipT-Primary & 17 & $65.4 \%$ & $10.1 \%$ & 9 & $34.6 \%$ & $15.3 \%$ \\
\hline & GradDipT-Secondary & 20 & $51.3 \%$ & $11.8 \%$ & 19 & $48.7 \%$ & $32.2 \%$ \\
\hline & BTchg (Hons) & 2 & $100 \%$ & $1.2 \%$ & & & \\
\hline \multirow[t]{4}{*}{ Year of study } & Year 1 & 41 & $75.9 \%$ & $24.3 \%$ & 13 & $24.1 \%$ & $22.0 \%$ \\
\hline & Year 2 & 54 & $80.6 \%$ & $32.0 \%$ & 13 & $19.4 \%$ & $22.0 \%$ \\
\hline & year 3 & 32 & $91.4 \%$ & $18.9 \%$ & 3 & $8.6 \%$ & $5.1 \%$ \\
\hline & Year $4+$ & 42 & $58.3 \%$ & $24.9 \%$ & 30 & $41.7 \%$ & $50.8 \%$ \\
\hline \multirow{3}{*}{$\begin{array}{l}\text { Length of web } \\
\text { site use }\end{array}$} & New user & 88 & $74.6 \%$ & $53.7 \%$ & 30 & $25.4 \%$ & $51.7 \%$ \\
\hline & 3 months -1 year & 36 & $90.0 \%$ & $22.0 \%$ & 4 & $10.0 \%$ & $6.9 \%$ \\
\hline & More than 1 year & 40 & $62.5 \%$ & $24.4 \%$ & 24 & $37.5 \%$ & $41.4 \%$ \\
\hline \multirow{2}{*}{$\begin{array}{l}\text { Internet access } \\
\text { at home }\end{array}$} & No & 19 & $61.3 \%$ & $11.2 \%$ & 12 & $38.7 \%$ & $20.3 \%$ \\
\hline & Yes & 150 & $76.1 \%$ & $88.8 \%$ & 47 & $23.9 \%$ & $79.7 \%$ \\
\hline Table Total & & 169 & $74.1 \%$ & $100 \%$ & 59 & $25.9 \%$ & $100 \%$ \\
\hline
\end{tabular}




\subsubsection{Age and Web site use}

The study found different use-patterns of the Internet and the Library's Web site according to the age category. The pattern is illustrated by Chart 4 below

The youngest group (16-21 years) shows a high Internet use. Nearly half of the respondents of this group $(48.8 \% ; 125)$ use the Internet but not the Library by remote access. Just over one-third $(34.4 \% ; 88)$ use the Library through the Web site and $16.8 \%$ (43) do not use the Internet at all.

In the second age category (22-27 years) the pattern is similar but not as pronounced. Both, that is Internet use but no Web site use $(43.1 \% ; 53)$ and Web site use $(40.7 ; 50)$, range within the lower $40 \%$ mark with a difference of only three respondents. $16.3 \%$ (20) of the respondents in this category do not use the Internet. This percentage is similar in the youngest age group.

The pattern changes for the next three age categories. Web site use is the highest use pattern in all of these categories, with percentages ranging between $46 \%$ and $59 \%$. The highest percentage of remote Library users are in the 28-34 age category, with $59.1 \%$ (39) of respondents using the Web site, followed by the $45+$ user group (47.4\% ;9) and the 35-44 user group $(46.7 \%$; 42).

Just over one-quarter of the respondents of all three age categories use the Internet, but not the Library by remote access. Percentages are very similar: $28.8 \%$ (19) of the 28-34 year olds, $28.9 \%$ (26) of the $35-44$ year old and $26.3 \%$ (5) of the $45+$ year olds. 
Internet use is higher within the 28-34 year olds compared to the two older age categories. Only $12.1 \%$ (8) respondents of this category reported not using the Internet. Percentages for the two older categories are very similar: $24.4 \%$ (22) of the $35-44$ year olds and $26.3 \%$ (5) of the $45+$ year olds do not use the Internet.

In order to perform a chi-square test the two oldest age categories had to be collapsed as the $45+$ age group had one expected count less than five. The chi-square test then found that there is a statistically significant relationship between age category, Internet use and remote use of the Library with $\mathrm{p}=.001$.

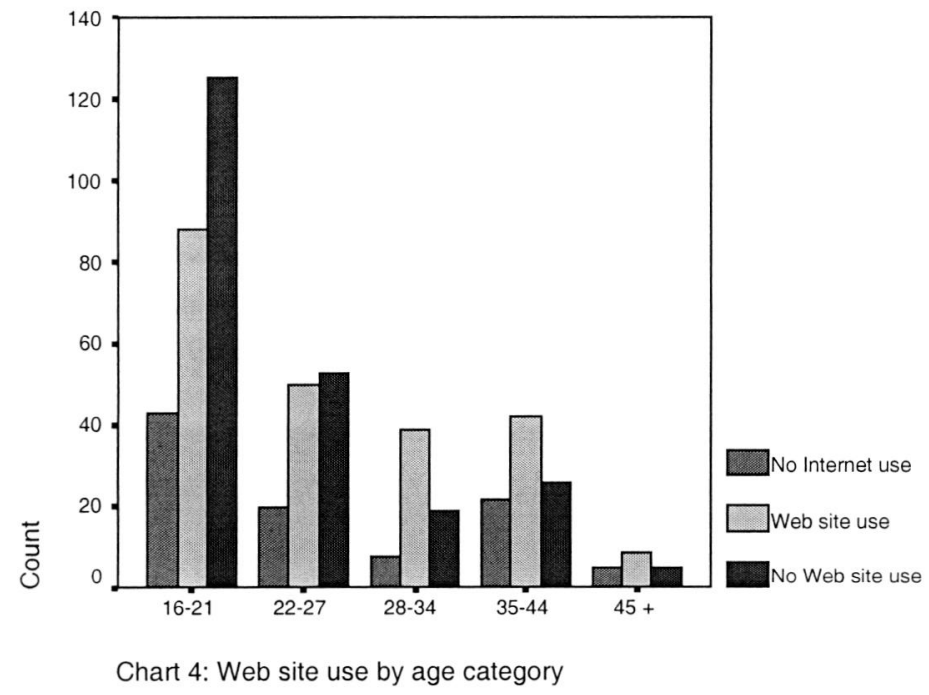

Table 5 below illustrates how long remote users have been using the Library by remote access and Internet access from home by age group. For this analysis the age groups 35-44 and 45+ have been collapsed. 
Over half of the two youngest age groups are new users of the Library's Web site.

Higher percentages of the two older age categories have been remote library users for more than a year. Internet access at home is highest for the two older age groups and lowest for the youngest age group.

\begin{tabular}{|c|c|c|c|c|c|c|c|c|c|}
\hline & & \multicolumn{8}{|c|}{ age category } \\
\hline & & \multicolumn{2}{|c|}{$16-21$} & \multicolumn{2}{|c|}{$22-27$} & \multicolumn{2}{|c|}{$28-34$} & \multicolumn{2}{|c|}{$35+$} \\
\hline & & Count & Col \% & Count & Col \% & Count & Col \% & Count & Col \% \\
\hline \multirow[t]{2}{*}{ Gender } & Female & 72 & $81.8 \%$ & 31 & $62.0 \%$ & 21 & $55.3 \%$ & 44 & $86.3 \%$ \\
\hline & Male & 16 & $18.2 \%$ & 19 & $38.0 \%$ & 17 & $44.7 \%$ & 7 & $13.7 \%$ \\
\hline \multirow[t]{2}{*}{ Status } & Undergraduate & 76 & $86.4 \%$ & 24 & $48.0 \%$ & 21 & $53.8 \%$ & 40 & $78.4 \%$ \\
\hline & Graduate & 12 & $13.6 \%$ & 26 & $52.0 \%$ & 18 & $46.2 \%$ & 11 & $21.6 \%$ \\
\hline \multirow{3}{*}{$\begin{array}{l}\text { Length of web } \\
\text { site use }\end{array}$} & New user & 51 & $58.6 \%$ & 30 & $61.2 \%$ & 19 & $48.7 \%$ & 19 & $40.4 \%$ \\
\hline & 3 months - 1 year & 17 & $19.5 \%$ & 8 & $16.3 \%$ & 3 & $7.7 \%$ & 12 & $25.5 \%$ \\
\hline & More than 1 year & 19 & $21.8 \%$ & 11 & $22.4 \%$ & 17 & $43.6 \%$ & 16 & $34.0 \%$ \\
\hline \multirow{3}{*}{$\begin{array}{l}\text { Internet access } \\
\text { at home } \\
\text { Table Total }\end{array}$} & No & 17 & $19.3 \%$ & 7 & $14.0 \%$ & 3 & $7.7 \%$ & 4 & $7.8 \%$ \\
\hline & Yes & 71 & $80.7 \%$ & 43 & $86.0 \%$ & 36 & $92.3 \%$ & 47 & $92.2 \%$ \\
\hline & & 88 & $100 \%$ & 50 & $100 \%$ & 39 & $100 \%$ & 51 & $100 \%$ \\
\hline
\end{tabular}

Table 5: Some characteristics of remote users by age $N=231$

\subsubsection{Status and Web site use}

There are different use-patterns for undergraduate and graduate students using the Library through the Web site, as illustrated in Chart 5 below.

Of all undergraduate students surveyed, 37.7\% (163) use the Library's Web site. The largest group of undergraduate students $(41.9 \% ; 181)$ uses the Internet, but not the Library by remote access. About one-fifth $(20.4 \% ; 88)$ do not use the Internet. 
Among graduate students surveyed, the largest group (54\%; 68) uses the Library by remote access. $37.3 \%$ (47) use the Internet without using the Library's Web site and $8.7 \%$ (11) do not use the Internet.

A chi-square test found that there are statistically significant differences between graduates' and undergraduates' use of the Internet and the Library by remote access $(\mathrm{p}=.001)$.

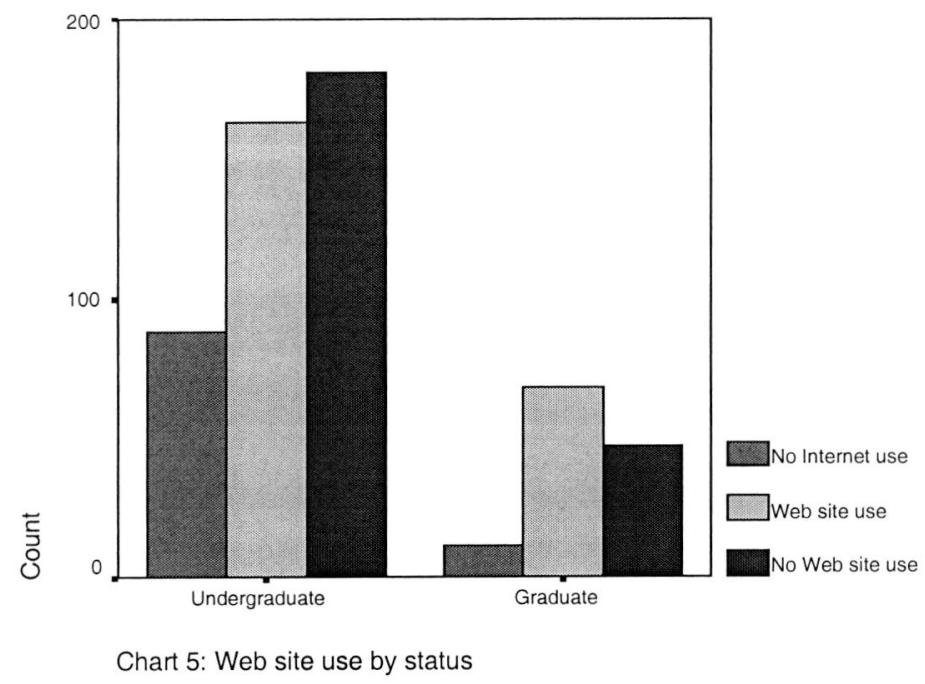

Percentages for both graduate $(53.7 \%)$ and undergraduate students $(53.8 \%)$ who are new users of the Library's Web site by remote access are similar (see Table 6 below). A higher percentage of graduate students (38.8\%) have been using the Library by remote access for more than a year compared to undergraduate students $(24.1 \%)$.

$3.9 \%$ more undergraduate students who are remote users of the Library have Internet access from home. 


\begin{tabular}{|c|c|c|c|c|c|c|c|}
\hline & & \multicolumn{6}{|c|}{ Status } \\
\hline & & \multicolumn{3}{|c|}{ Undergraduate } & \multicolumn{3}{|c|}{ Graduate } \\
\hline & & Count & Col \% & $\begin{array}{c}\text { Row } \\
\%\end{array}$ & Count & Col \% & $\begin{array}{c}\text { Row } \\
\%\end{array}$ \\
\hline \multirow{3}{*}{$\begin{array}{l}\text { Length of web } \\
\text { site use }\end{array}$} & New user & 85 & $53.8 \%$ & $70.2 \%$ & 36 & $53.7 \%$ & $29.8 \%$ \\
\hline & $\begin{array}{l}3 \text { months - } 1 \\
\text { year }\end{array}$ & 35 & $22.2 \%$ & $87.5 \%$ & 5 & $7.5 \%$ & $12.5 \%$ \\
\hline & More than 1 year & 38 & $24.1 \%$ & $59.4 \%$ & 26 & $38.8 \%$ & $40.6 \%$ \\
\hline \multirow{2}{*}{$\begin{array}{l}\text { Internet access } \\
\text { at home }\end{array}$} & No & 20 & $12.3 \%$ & $64.5 \%$ & 11 & $16.2 \%$ & $35.5 \%$ \\
\hline & Yes & 143 & $87.7 \%$ & $71.5 \%$ & 57 & $83.8 \%$ & $28.5 \%$ \\
\hline Table Total & & 163 & $100 \%$ & $70.6 \%$ & 68 & $100 \%$ & $29.4 \%$ \\
\hline
\end{tabular}

Table 6: Some characteristics of remote users by status $\quad \mathrm{N}=231$

\subsubsection{Year of study and Web site use}

As illustrated in Chart 6 below, year 1 and 3 as well as year 2 and $4+$ have similar use- patterns. Year 1 and 3 show a use-pattern which was found typical for undergraduate students, whereas year 2 and 4+ display the same use-pattern found for graduate students (see Chart 5 above).

The percentages of students using the Library's Web site for year 1 and 3 are very similar: $32 \%$ (55) of year 1 students and $29.2 \%$ (35) of year 3 students use the Library by remote access. The percentages for year 2 and 4 students are higher than for year 1 and 3 students, but also similar: $53.5 \%$ (68) of year 2 students and $52.2 \%$ (72) of year 4+ students use the Library's Web site.

These percentages are reversed for students who use the Internet, but not the Library by remote access. $42.4 \%$ (73) of year 1 students and 50\% (60) of year 3 students are general Internet users. In comparison 33.1\% (42) of year 2 and $38.4 \%$ (53) of year 4+ students use the Internet, but not the Library's Web site. 
Non-use of the Internet is higher among year 1 and year 3 students: $25.6 \%$ (44) of year 1 students and $20.8 \%$ (25) of year 3 students do not use the Internet. Year 4+ students have the smallest group of non-users of the Internet $(9.4 \% ; 13)$, followed by year 2 students of whom $13.4 \%$ (17) are not using the Internet.

The chi-square test showed statistically significant differences between the year of study and Internet and remote Library use $(\mathrm{p}=.000)$.

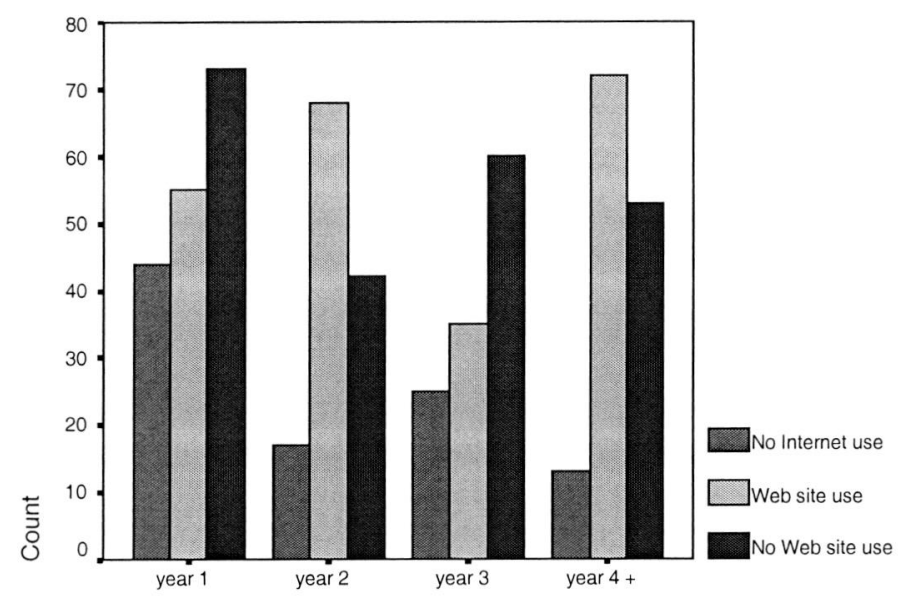

Chart 6: Web site use by year of study

Table 7 below describes further some characteristics of the remote user group by year of study.

90.6\% (48) of year 1 students are new users and around one-third of year 2 and year 3 students have been using the Library by remote access for either up to 3 months, 3 months to 1 year or more than 1 year. Year $4+$ students are either new users or they have been using the Library's Web site for more than 1 year.

Access from home varies only slightly, but is highest among year 3 students. 


\begin{tabular}{|c|c|c|c|c|c|c|c|c|c|}
\hline & & \multicolumn{8}{|c|}{ Year of study } \\
\hline & & \multicolumn{2}{|c|}{ Year 1} & \multicolumn{2}{|c|}{ Year 2} & \multicolumn{2}{|c|}{ year 3} & \multicolumn{2}{|c|}{ Year $4+$} \\
\hline & & Count & $\mathrm{Col} \%$ & Count & Col \% & Count & Col \% & Count & $\mathrm{Col} \%$ \\
\hline \multirow{3}{*}{$\begin{array}{l}\text { Length of web } \\
\text { site use }\end{array}$} & New user & 48 & $90.6 \%$ & 25 & $38.5 \%$ & 12 & $34.3 \%$ & 35 & $49.3 \%$ \\
\hline & 3 months - 1 year & 2 & $3.8 \%$ & 20 & $30.8 \%$ & 12 & $34.3 \%$ & 6 & $8.5 \%$ \\
\hline & More than 1 year & 3 & $5.7 \%$ & 20 & $30.8 \%$ & 11 & $31.4 \%$ & 30 & $42.3 \%$ \\
\hline \multirow{3}{*}{$\begin{array}{l}\text { Internet access } \\
\text { at home } \\
\text { Table Total }\end{array}$} & No & 7 & $12.7 \%$ & 9 & $13.2 \%$ & 4 & $11.4 \%$ & 11 & $15.3 \%$ \\
\hline & Yes & 48 & $87.3 \%$ & 59 & $86.8 \%$ & 31 & $88.6 \%$ & 61 & $84.7 \%$ \\
\hline & & 55 & $100 \%$ & 68 & $100 \%$ & 35 & $100 \%$ & 72 & $100 \%$ \\
\hline
\end{tabular}

Table 7: Some characteristics of remote users by year of study $N=231$

\subsubsection{Programme and Web site use}

Chart 7 illustrates use-patterns by students enrolled in the different teacher education programmes (see 3.2).

Two of the programmes represented in the sample are very small. A total of 13 students are enrolled in the BTchg-Hons programme. Nearly all of these students (10) were surveyed. 59 students are enrolled in the Ropu Rumaki programme. As only year 1 and 3 students were captured by the survey, the number of Ropu Rumaki students represented in the sample is small (13 students).

Three programmes show a similar use-pattern to that found before for graduate students. They are: BTchg-Secondary Cojoint, GradDipT-Primary and GradDipTSecondary. Percentages do not vary much between them.

In each programme more than half of the respondents use the Library's Web site. The remote use of the Library ranges between $54 \%$ and $60.9 \%$. GradDipT-Secondary 
students have the highest use. $60.9 \%$ (39) of this group use remote access to the Library. The second highest user group are the BTchg-Secondary Cojoint students of whom $54.9 \%$ (28) use the Library's Web site, closely followed by 54\% (27) GradDipT-Primary students.

The figures for general Internet use (no Web site use) are also similar and range from $34.4 \%$ (22) for the GradDipT-Secondary students, 37.3\% (19) for the BTchgSecondary Cojoint students and 40\% (20) for the GradDipT-Primary students.

No Internet use is low among these three groups. 7.8\% (4) of the BTchg-Secondary Cojoint students, $6 \%$ (3) of the GradDipT-Primary students and $4.7 \%$ (3) of the GradDipT-Secondary students do not use the Internet.

Of these three groups, the GradDipT-Secondary students have the highest proportion of Internet and Web site use. The distribution of the percentages for GradDipTPrimary and BTchg- Secondary Cojoint students is very similar.

BTchg-Early Childhood and BTchg-Hons students show a different but similar usepattern. Similar proportions of respondents do not use the Internet: $34.4 \%$ (31) of BTchg-Early Childhood students and 40\% (4) of BTchg-Hons students.

$35.6 \%$ (32) of the BTchg-Early Childhood students and $40 \%$ (4) of the BTchg-Hons students use and Internet, but not the Library by remote access. Just under one-third $(30 \% ; 27)$ of students enrolled in the BTchg-Early Childhood programme and one- 
fifth $(20 \% ; 2)$ of students enrolled in the BTchg-Hons programme use the Library by remote access.

Students enrolled in the main teacher education programme for primary teachers (BTchg-Primary) are the only group which shows the use-pattern previously found typical for undergraduate students. $46.1 \%$ (129) of these students use the Internet, but not the Library's Web site, $36.8 \%$ (103) use the Library by remote access and $17.1 \%$ (48) do not use the Internet.

The small group of Ropu Rumaki students ( $\mathrm{N}=13)$ surveyed display a unique usepattern previously not found. $46.2 \%$ (6) do not use the Internet. Of the $53.8 \%$ (7) students who use the Internet, $38.5 \%$ (5) use the Library by remote access.

A chi-square test could not be performed as four cells had expected counts less than 5 because of the small size of the BTchg Hons and Ropu Rumaki programmes represented in the sample. In order to perform a chi-square test these two programmes were removed. The chi-square test then showed a statistically significant difference between programme, Internet use and remote use of the Library $(\mathrm{p}=000)$. 


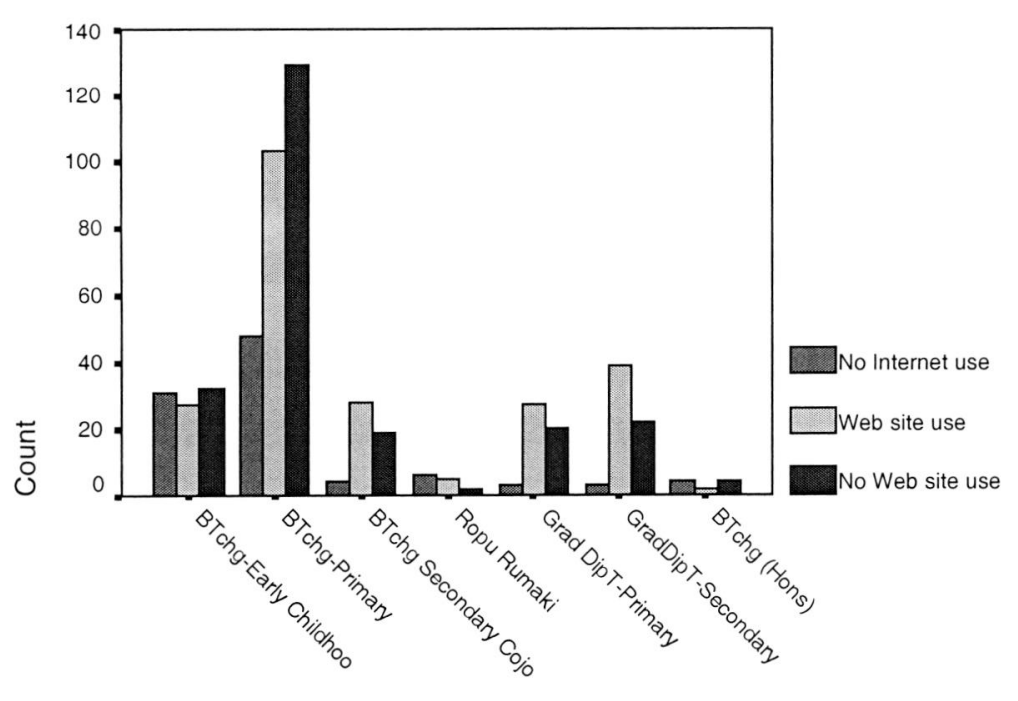

Chart 7: Web site use by programme

Table 8 (see next page) summarises some characteristics of the remote user group by programme.

High proportions of BTchg-Primary (46.1\%) and BTchg-Secondary Cojoint (64.3\%) and Ropu Rumaki (60\%) students are in the 16-21 age group. Most of the BTchgEarly Childhood students are spread evenly among the 16-21, 28-34 and 35-44 age groups. The majority of students enrolled in both GradDipT programmes are in the 22-27 and 28-34 age groups.

More than half $(55.6 \%)$ of remote users enrolled in the BTchg-Early Childhood programme are in their second year of study. The majority of BTchg-Secondary Cojoint students are either in their second $(39.3 \%)$ or third year $(32.1 \%)$ of study. In comparison the majority of students enrolled in the BTchg-Primary programme are in their first year $(40.8 \%)$ or second year of study $(40.8 \%) .17 .5 \%$ of students enrolled in this programme are in their third year of study. 


\begin{tabular}{|c|c|c|c|c|c|c|c|c|c|c|c|c|c|c|c|}
\hline & & \multicolumn{14}{|c|}{ Programme } \\
\hline & & \multicolumn{2}{|c|}{$\begin{array}{l}\text { BTchg-Early } \\
\text { Childhood }\end{array}$} & \multicolumn{2}{|c|}{ BTchg-Primary } & \multicolumn{2}{|c|}{$\begin{array}{l}\text { BTchg } \\
\text { Secondary } \\
\text { Cojoint }\end{array}$} & \multicolumn{2}{|c|}{ Ropu Rumaki } & \multicolumn{2}{|c|}{$\begin{array}{c}\text { Grad } \\
\text { DipT-Primary }\end{array}$} & \multicolumn{2}{|c|}{$\begin{array}{c}\text { GradDipT-Sec } \\
\text { ondary }\end{array}$} & \multicolumn{2}{|c|}{ BTchg (Hons) } \\
\hline & & Count & $\begin{array}{c}\mathrm{Col} \\
\% \\
\end{array}$ & $\begin{array}{c}\text { Coun } \\
t\end{array}$ & $\mathrm{Col} \%$ & Count & Col \% & Count & Col \% & Count & Col \% & Count & $\begin{array}{c}\text { Col } \\
\% \\
\end{array}$ & Count & $\mathrm{Col} \%$ \\
\hline \multirow{5}{*}{ Age category } & $16-21$ & 8 & $30.8 \%$ & 47 & $46.1 \%$ & 18 & $64.3 \%$ & 3 & $60.0 \%$ & 5 & $19.2 \%$ & 7 & $17.9 \%$ & & \\
\hline & $22-27$ & 1 & $3.8 \%$ & 15 & $14.7 \%$ & 7 & $25.0 \%$ & 1 & $20.0 \%$ & 11 & $42.3 \%$ & 14 & $35.9 \%$ & 1 & $50.0 \%$ \\
\hline & $28-34$ & 8 & $30.8 \%$ & 11 & $10.8 \%$ & 2 & $7.1 \%$ & & & 6 & $23.1 \%$ & 12 & $30.8 \%$ & & \\
\hline & $35-44$ & 8 & $30.8 \%$ & 22 & $21.6 \%$ & 1 & $3.6 \%$ & 1 & $20.0 \%$ & 3 & $11.5 \%$ & 6 & $15.4 \%$ & 1 & $50.0 \%$ \\
\hline & $45+$ & 1 & $3.8 \%$ & 7 & $6.9 \%$ & & & & & 1 & $3.8 \%$ & & & & \\
\hline \multirow[t]{4}{*}{ Year of study } & Year 1 & 6 & $22.2 \%$ & 42 & $40.8 \%$ & 4 & $14.3 \%$ & 3 & $60.0 \%$ & & & & & & \\
\hline & Year 2 & 15 & $55.6 \%$ & 42 & $40.8 \%$ & 11 & $39.3 \%$ & & & & & & & & \\
\hline & year 3 & 6 & $22.2 \%$ & 18 & $17.5 \%$ & 9 & $32.1 \%$ & 2 & $40.0 \%$ & & & & & & \\
\hline & Year $4+$ & & & 1 & $1.0 \%$ & 4 & $14.3 \%$ & & & 26 & $100 \%$ & 39 & $100 \%$ & 2 & $100.0 \%$ \\
\hline \multirow{3}{*}{$\begin{array}{l}\text { Length of web } \\
\text { site use }\end{array}$} & New user & 10 & $38.5 \%$ & 64 & $64.6 \%$ & 9 & $32.1 \%$ & 2 & $40.0 \%$ & 17 & $63.0 \%$ & 19 & $50.0 \%$ & & \\
\hline & $\begin{array}{l}3 \text { months - } 1 \\
\text { year }\end{array}$ & 9 & $34.6 \%$ & 18 & $18.2 \%$ & 8 & $28.6 \%$ & & & 2 & $7.4 \%$ & 2 & $5.3 \%$ & 1 & $50.0 \%$ \\
\hline & $\begin{array}{l}\text { More than } 1 \\
\text { year }\end{array}$ & 7 & $26.9 \%$ & 17 & $17.2 \%$ & 11 & $39.3 \%$ & 3 & $60.0 \%$ & 8 & $29.6 \%$ & 17 & $44.7 \%$ & 1 & $50.0 \%$ \\
\hline \multirow{2}{*}{$\begin{array}{l}\text { Internet access } \\
\text { at home }\end{array}$} & No & 2 & $7.4 \%$ & 12 & $11.7 \%$ & 4 & $14.3 \%$ & 2 & $40.0 \%$ & 5 & $18.5 \%$ & 6 & $15.4 \%$ & & \\
\hline & Yes & 25 & $92.6 \%$ & 91 & $88.3 \%$ & 24 & $85.7 \%$ & 3 & $60.0 \%$ & 22 & $81.5 \%$ & 33 & $84.6 \%$ & 2 & $100.0 \%$ \\
\hline Table Total & & 27 & $100 \%$ & 103 & $100 \%$ & 28 & $100 \%$ & 5 & $100 \%$ & 27 & $100 \%$ & 39 & $100 \%$ & 2 & $100.0 \%$ \\
\hline
\end{tabular}

Table 8: Some characteristics of remote users by programme $N=231$ 
BTchg-Primary (64.6\%), GradDipT-Primary (63\%) and GradDipT-Secondary (50\%) have the highest proportions of new users. Btchg-Early Childhood and BTchgSecondary Cojoint students are fairly evenly spread among the three categories. The two GradDipT programmes and Ropu Rumaki students have the highest proportions of long-term users (more than 1 year).

Students enrolled in the BTchg-Early Childhood programmes have the highest percentage of Internet access from home.

\subsubsection{Part-time or full-time study and Web site use}

There are few part-time students enrolled in the selected programmes. The sample of students surveyed is very small $(\mathrm{N}=13)$.

Compared to full-time students, part-time students stated a slightly higher use of the Library by remote access. $46.2 \%$ (6) of part-time students and $41.3 \%$ (225) of fulltime students use the Library's Web site. Internet use is higher among full-time students: $41.3 \%$ (225) of full-time students use the Internet, but not the Library's Web site compared to $23.1 \%$ (3) part-time students. 30.8\% (4) part-time students and $17.4 \%(95)$ of full-time students do not use the Internet.

The chi-square test performed had 1 cell with an expected count less than 5 due to the small sample size of part-time students. Part-time students could not be further analysed here because of the small sample size. 


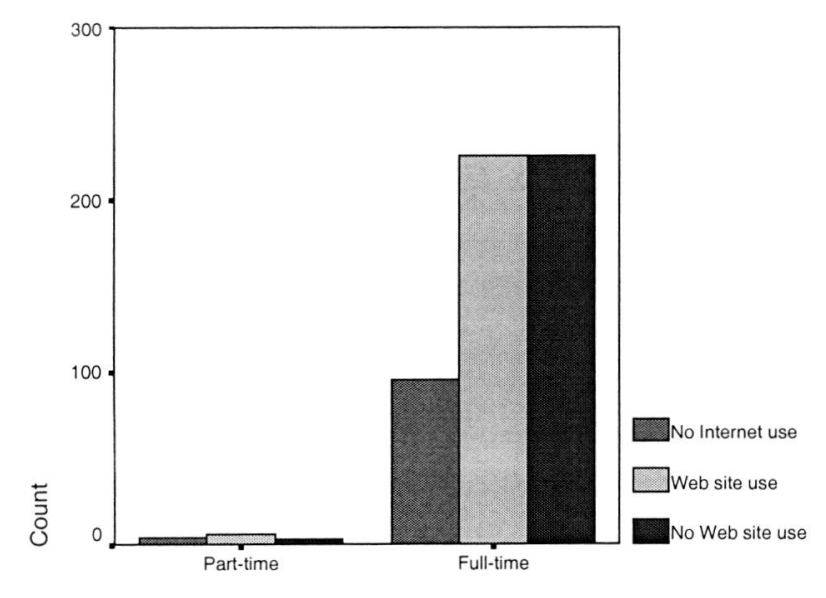

Chart 8: Web site use by full-time or part-time study 


\subsection{Impact of remote Library use on the use of the Library in-house}

Reported below are the survey findings as they relate to and provide information on the possible impact of remote Library use on the use of the Library in-house. As stated in the term definitions (see 1.7), remote users are students who use the Library by remote access and/or in-house in comparison to in-house only users who do not use the Library by remote access.

\section{RQ 5: Which Library services and resources do students use in-house and by remote access respectively?}

\subsubsection{Services and resources used in-house}

Table 9 below shows which resources and services students use in the Library inhouse sorted by frequency of use. Most often used by all students are Search materials on the shelf (77.1\%), Photocopy (76.7\%), and Borrow items (72.2\%).

Over half of the respondents use Desk copy (67\%), Catalogue (64.3\%) and Consult librarian $(57.3 \%)$. More than one-third of the respondents stated to Use the reference collection $(42.1 \%)$ and Use the Internet $(37.8 \%)$. The following services are used by around one-quarter of the respondents: Recall items (27.1\%), Databases (26\%), Borrower information/renewals/requests (24.9\%) and Study/Group study (23.7\%).

Interloan is used by a much smaller group $(6.8 \%)$ of the students surveyed. $2.5 \%$ of the respondents stated they are not using the Library. 
Table 9 presents separate figures for those students who use the Library by remote access and those who are in-house only users of the Library. The percentage given in brackets below is the difference between the percentage of remote users and in-house only users in their use of the library services and resources in-house.

\begin{abstract}
All services and resources except for study/group study are used by a higher percentage of remote users compared to in-house only users.
\end{abstract}

There are small differences between remote and in-house only users in the use of the following services and resources: Borrow items (0.8\%), Desk copy (1.6\%), Consult Librarian (1.8\%), Photocopy (2.9\%). A slightly higher percentage (1.3\% more) of inhouse only users stated using Study/Group study.

Greater differences between remote and in-house only users were found in the use of

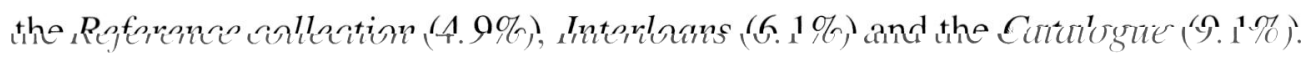

Differences of more than $10 \%$ between remote and in-house only users were found in their use the following services and resources: Search for materials on shelf (10.3\%), Borrower information/renewals/requests (12.9\%), Use of Databases (16.2\%) and Use of the Internet $(16.7 \%)$.

Of the 14 respondents who do not use the Library in-house, two stated that they use the Library by remote access. 


\begin{tabular}{|c|c|c|c|c|c|}
\hline & & & Librar & users & \\
\hline & & & $\begin{array}{c}\text { Remote } \\
\text { users }\end{array}$ & $\begin{array}{c}\text { In-house } \\
\text { only } \\
\text { users }\end{array}$ & Total \\
\hline Library & Search for materials & Count & 192 & 238 & 430 \\
\hline services & on shelf & Column \% & 83.1 & 72.8 & 77.1 \\
\hline used & Photocopy & Count & 181 & 247 & 428 \\
\hline & & Column \% & 78.4 & 75.5 & 76.7 \\
\hline & Borrow items & Count & 168 & 235 & 403 \\
\hline & & Column \% & 72.7 & 71.9 & 72.2 \\
\hline & Desk copy & Count & 157 & 217 & 374 \\
\hline & & Column \% & 68.0 & 66.4 & 67.0 \\
\hline & Catalogue & Count & 161 & 198 & 359 \\
\hline & & Column \% & 69.7 & 60.6 & 64.3 \\
\hline & Consult librarian & Count & 135 & 185 & 320 \\
\hline & & Column \% & 58.4 & 56.6 & 57.3 \\
\hline & Use the reference & Count & 104 & 131 & 235 \\
\hline & collection & Column \% & 45.0 & 40.1 & 42.1 \\
\hline & Use the Internet & Count & 110 & 101 & 211 \\
\hline & & Column \% & 47.6 & 30.9 & 37.8 \\
\hline & Recall items & Count & 75 & 76 & 151 \\
\hline & & Column \% & 32.5 & 23.2 & 27.1 \\
\hline & Databases & Count & 82 & 63 & 145 \\
\hline & & Column \% & 35.5 & 19.3 & 26.0 \\
\hline & Borrower & Count & 75 & 64 & 139 \\
\hline & information/renewal & Column \% & 32.5 & 19.6 & 24.9 \\
\hline & Study/Group study & Count & 53 & 79 & 132 \\
\hline & & Column \% & 22.9 & 24.2 & 23.7 \\
\hline & Interloan items & Count & 24 & 14 & 38 \\
\hline & & Column \% & 10.4 & 4.3 & 6.8 \\
\hline & None & Count & 2 & 12 & 14 \\
\hline & & Column \% & .9 & 3.7 & 2.5 \\
\hline Total & Count & & 231 & 327 & 558 \\
\hline & Column \% & & 100.0 & 100.0 & 100.0 \\
\hline
\end{tabular}

Table 9: Library services/resources used in-house by remote and in-house only users

\subsubsection{Services and resources used by remote access}

Table 10 illustrates the remote use of Library services and resources by undergraduate and graduate students.

The Library's web-based catalogue was the most frequently resource used by the students who use the Library by remote access $(\mathrm{N}=228) .81 .6 \%$ of all students stated they use the catalogue for searches, 39\% use abstract and full-text databases, $35.1 \%$ check their borrower information and $17.1 \%$ recall items by remote access. 
More graduate students recall items by remote access (26.9\% graduates, $13 \%$ undergraduates) and accessed their borrower information (40.3\% graduates, $32.9 \%$ undergraduates). More undergraduate students used databases by remote access (40.4\% undergraduates, $35.8 \%$ graduates) and the catalogue (82\% undergraduates, $80.6 \%$ graduates).

\begin{tabular}{|lll|r|r|r|}
\hline & & \multicolumn{2}{|c|}{ Status } & \\
\cline { 4 - 5 } & & Undergra & \\
duate & Graduate & Total \\
\hline Library & Catalogue & Count & 132 & 54 & 186 \\
services/resources & & Column \% & 82.0 & 80.6 & 81.6 \\
used by remote & Recalls & Count & 21 & 18 & 39 \\
access & & Column \% & 13.0 & 26.9 & 17.1 \\
& Databases & Count & 65 & 24 & 89 \\
& & Column \% & 40.4 & 35.8 & 39.0 \\
& Borrower information & Count & 53 & 27 & 80 \\
Total & Column \% & 32.9 & 40.3 & 35.1 \\
& Count & & 161 & 67 & 228 \\
& Column \% & 100.0 & 100.0 & 100.0 \\
\hline
\end{tabular}

Table 10: Library services/resources used by remote access

\subsubsection{Frequency and length of in-house Library visits}

RQ 6: How often do students visit the Library in-house and how much time do they spend on average at each visit?

Table 11 below summarizes the frequency of visits to the Library by respondents. $5.9 \%$ (33) students did not answer this question, which brings the total number of respondents to $\mathrm{N}=525$.

More than half $(59.2 \%)$ of the students questioned visit the Library weekly. Nearly one-fifth (18.7\%) are in the Library daily. About one-tenth of all respondents go to the 
Library monthly $(10.3 \%)$ or rarely $(9.3 \%) .2 .5 \%$ of the respondents never visit the Library.

\begin{tabular}{|c|c|c|c|c|c|c|c|}
\hline & & & & & & \multicolumn{2}{|c|}{ Group Total } \\
\hline & & \multicolumn{2}{|c|}{ Remote users } & \multicolumn{2}{|c|}{ In-house only users } & \multirow[b]{2}{*}{ Count } & \multirow[b]{2}{*}{ Col \% } \\
\hline & & Count & $\mathrm{Col} \%$ & Count & $\mathrm{Col} \%$ & & \\
\hline \multicolumn{2}{|c|}{ Freqency of Daily } & 53 & $23.9 \%$ & 45 & $14.9 \%$ & 98 & $18.7 \%$ \\
\hline \multirow{4}{*}{$\begin{array}{l}\text { Library } \\
\text { visits }\end{array}$} & Weekly & 117 & $52.7 \%$ & 194 & $64.0 \%$ & 311 & $59.2 \%$ \\
\hline & Monthly & 29 & $13.1 \%$ & 25 & $8.3 \%$ & 54 & $10.3 \%$ \\
\hline & Rarely & 22 & $9.9 \%$ & 27 & $8.9 \%$ & 49 & $9.3 \%$ \\
\hline & Never & 1 & $.5 \%$ & 12 & $4.0 \%$ & 13 & $2.5 \%$ \\
\hline \multicolumn{2}{|c|}{ Group Total } & 222 & $100.0 \%$ & 303 & $100.0 \%$ & 525 & $100.0 \%$ \\
\hline
\end{tabular}

Table 11: Frequency of Library visits by remote and in-house only users

Table 11 lists the differences in the frequency of visits to the Library between students who also use the Library by remote access and those who use the Library only inhouse.

Both groups most often visit the Library weekly $(52.7 \%$ of remote users, $64 \%$ of inhouse only users). A higher percentage of remote users (23.9\%) go to the Library daily compared to $14.9 \%$ of in-house only users. Remote users also visit the Library more often on a monthly basis $(13.1 \%)$ than in-house only users $(8.3 \%)$.

$9.9 \%$ of remote users and $8.9 \%$ of in-house users only rarely visited the Library. Of the $2.5 \%$ of respondents who do not visit the Library in-house, $0.5 \%$ visit the Library by remote access.

A chi-square test found a statistically significant difference between remote users and in-house only users in relation to how often they visit the physical library $(\mathrm{p}=.001)$. 
Table 12 below summarizes how much time students spend on average at each visit to the Library in-house. $6.6 \%$ (37) of all respondents who visit the Library in-house did not answer this question $(\mathrm{N}=508)$.

Just over one-third of all respondents to this question (35.4\%) spend up to 30 minutes and over one-quarter (27.6\%) up to one hour at in the Library at each visit. About one- fifth $(20.5 \%)$ spend up to 15 minutes in the Library.

A smaller number averaged one to two hours in the Library $(13.8 \%)$ or more than two hours $(2.8 \%)$.

\begin{tabular}{|c|c|c|c|c|c|c|c|}
\hline & & & & & \multicolumn{2}{|c|}{ Group Total } \\
\hline & & \multicolumn{2}{|c|}{ Remote users } & \multicolumn{2}{|c|}{ In-house only users } & \multirow[b]{2}{*}{ Count } & \multirow[b]{2}{*}{ Col \% } \\
\hline & & Count & $\mathrm{Col} \%$ & Count & $\mathrm{Col} \%$ & & \\
\hline \multirow{5}{*}{$\begin{array}{l}\text { Time spent } \\
\text { in Library }\end{array}$} & up to $15 \mathrm{~min}$. & 45 & $20.7 \%$ & 59 & $20.3 \%$ & 104 & $20.5 \%$ \\
\hline & up to $30 \mathrm{~min}$. & 79 & $36.4 \%$ & 101 & $34.7 \%$ & 180 & $35.4 \%$ \\
\hline & up to 1 hour & 54 & $24.9 \%$ & 86 & $29.6 \%$ & 140 & $27.6 \%$ \\
\hline & $1-2$ hours & 31 & $14.3 \%$ & 39 & $13.4 \%$ & 70 & $13.8 \%$ \\
\hline & $>2$ hours & 8 & $3.7 \%$ & 6 & $2.1 \%$ & 14 & $2.8 \%$ \\
\hline \multicolumn{2}{|l|}{ Group Total } & 217 & $100.0 \%$ & 291 & $100.0 \%$ & 508 & $100.0 \%$ \\
\hline
\end{tabular}

Table 12: Time spent in the Library by remote and in-house only users

Table 12 provides separate figures for remote and in-house only users. Percentages for both groups are very similar. The largest difference (4.7\%) between the two user groups is between students who spend up to 1 hour in the Library. $29.6 \%$ of in-house only users and $24.9 \%$ of remote users stated that they spend up to 1 hour on average at each visit to the Library. 
A chi-square test found no statistically significant difference between the amount of time remote users and in-house only users spend in the Library $(\mathrm{p}=.670)$.

The following two charts combine the frequency of visits to the Library in-house and the time spent on average at each visits for remote uses (Chart 10) and in-house only users (Chart 9). For this analysis the categories monthly and rarely were collapsed into one new category monthly or less and the categories 1-2 hours and more than 2 hours were combined into a new category: more than 1 hour.

As shown in Table 11 greater percentages of remote users visit the Library daily, monthly or rarely compared to in-house only users whereas a greater percentage of inhouse only users visit the Library on a weekly basis.

As illustrated in Chart 9 and 10 below, nearly half of in-house only users surveyed $(47.5 \%)$ come to the Library on a weekly basis and stay up to 30 minutes or up to one hour compared to just over one-third (34.7\%) of all remote users surveyed.

$42.2 \%$ of remote users who visit the Library on a monthly basis stay for up to 15 minutes, compared to $28.3 \%$ of in-house only users.

On the other hand, $24.5 \%$ of remote users who on average spend up to one hour in the Library and $46.2 \%$ of remote users who on average spend more than one hour in the Library at each visit do so daily, compared to $11.9 \%$ and $29.5 \%$ of in-house only Library users. 
$14.3 \%$ (31) of all remote users surveyed visit the Library daily for between 30 minutes to more than one hour. This compares to $8.1 \%$ (23) in-house only Library users.

$16.2 \%$ (35) of all remote users surveyed who visit the Library monthly or less come in for up to 30 minutes compared to $10.6 \%$ (30) in-house only Library users. A greater percentage $(7.4 \% ; 16)$ of remote users who come in monthly or less also stay longer in the Library compared to $6 \%(17)$ in-house only users.

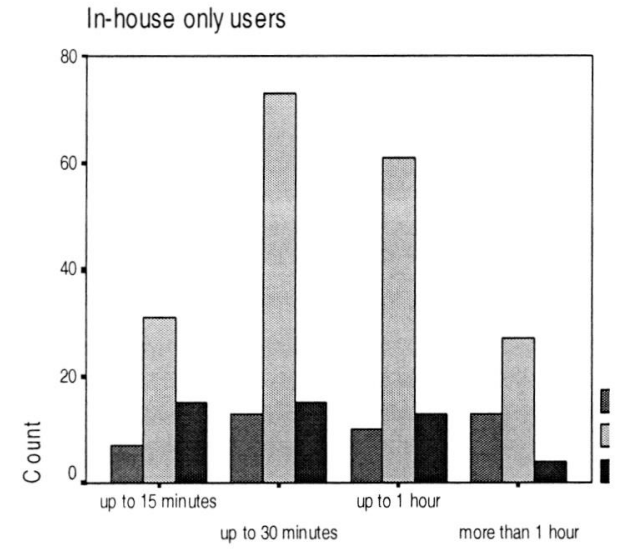

Chart 9: Time spent $x$ frequency of visits in-house

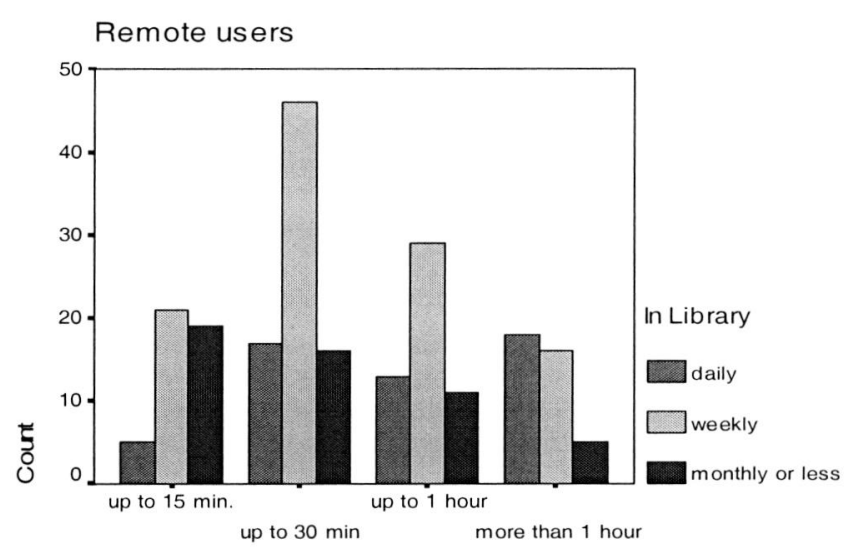

Chart 10: Time spent $x$ frequency of visits in-house

\subsubsection{Frequency and lengths of remote Library visits}

RQ 7: How often do students visit the Library by remote access and how much time do they spend on average at each visit? 
9.6\% (22) of the respondents who used the Library by remote access did not provide information on how often they visit the Library by remote access. The total number of students surveyed who responded to this question is $\mathrm{N}=207$.

As illustrated in Chart 11 below, only a small number $(4.8 \% ; 10)$ of students visit the Library daily by remote access. The largest group of remote users $(43 \% ; 89)$ use the Library's Web site on a weekly basis. Over half $(52.2 \%, 108)$ of all respondents to this question use the Library by remote access either monthly $(22.2 \% ; 46)$ or rarely $(30 \% ; 62)$

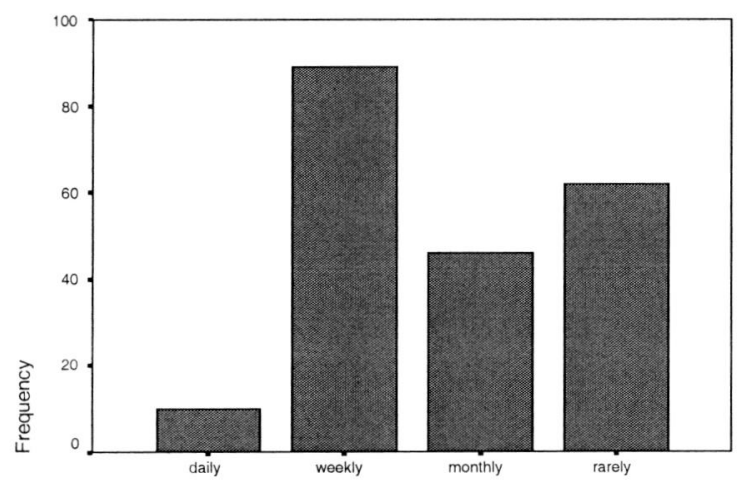

Chart 11: Frequency of remote Library visits

Chart 12 below illustrates how much time remote students spend when they visit the Library by remote access. Three-quarters of the respondents $(75.3 \%)$ logged into the Library for up to 30 minutes. Of those $42.6 \%$ logged in for up to 15 minutes and $32.6 \%$ for 30 minutes.

Nearly one-fifth (18.9\%) use the Library by remote access for up to one hour. $5.8 \%$ stay more than one hour. 17\% (39) of all remote users did not answer this question. As both categories 1-2 hours and more than two hours had few respondents they have 
been collapsed into a new category called more than one hour for the illustration of the results.

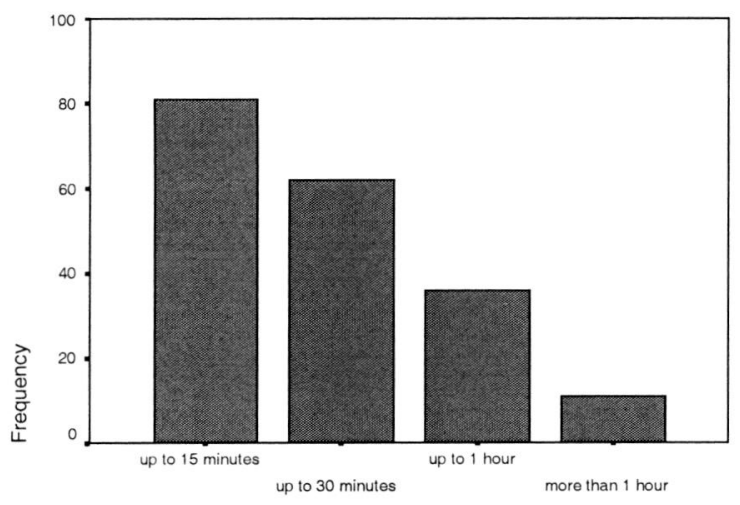

Chart 12: Time spent on remote Library use

Chart 13 below combines the frequency of visits to the Library by remote access and the time spent on average at each visit. Categories of the length of time spent on average at each visit were further collapsed to illustrate the differences between remote users who visit the Library a shorter time (up to 30 minutes) and those who visit a longer time (more than 30 minutes) by remote access.

The majority of remote users $(74.7 \% ; 139)$ visit the Library for up to 30 minutes. One-quarter of all remote users $(25.3 \%)$ surveyed spend more than 30 minutes at each visit.

Over half $(55.4 \% ; 77)$ of those respondents who visit the Library by remote access for up to 30 minutes do so monthly or less. $43.6 \%$ (62) of this group visit the Library's Web site more frequently (daily and weekly). 
In comparison, over half $(63.8 \% ; 30)$ of the remote users who spend more than 30 minutes at each remote Library visit logged into the Library's Web site more frequently (daily or weekly).

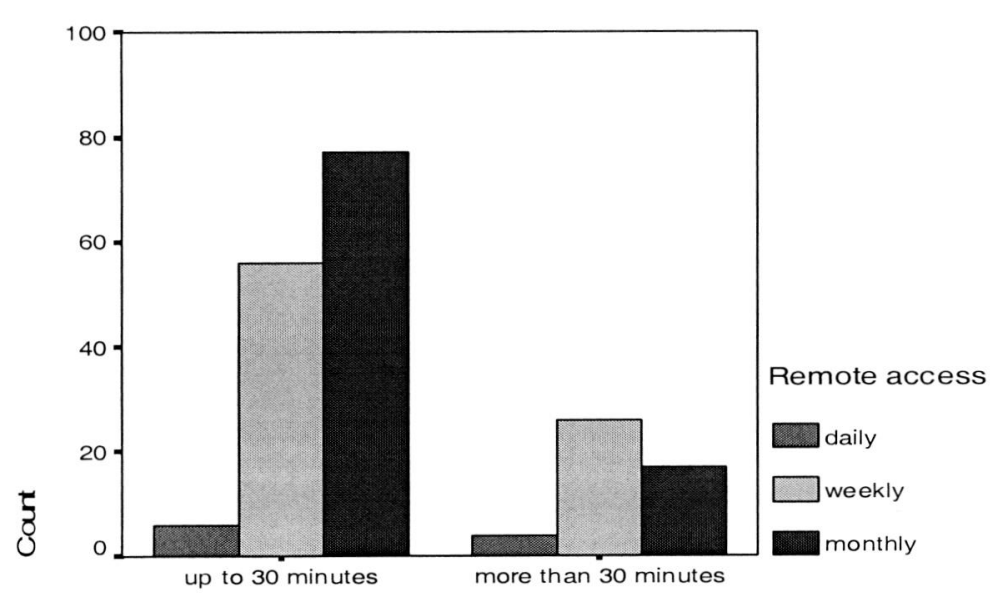

Chart 13: Time spent $x$ frequency of visits by remote access

\title{
5.4.5 Changes to the number of visits and the time spent in the Library
}

RQ 8: Does remote use of the Library change the number of visits to the Library and/or the time spent in the Library?

\author{
Respondents who use the Library by remote access were asked if the use of the \\ Library's Web site changed the frequency of their in-house library visits and/or the \\ time they spend in the Library.
}

Chart 14 and 15 below show the pattern of responses to changes to the frequency of visits to the Library and time spent in the Library. For about $60 \%$ of respondents there were no changes. $64.1 \%$ (141) did not change the frequency of their visits to the 
Library and $63.4 \%$ (142) did not change the time they spent on average at each visit in the Library.

$23.6 \%$ (52) of the respondents stated that they use the Library more frequently inhouse. About the same number $(24.6 \% ; 55)$ stated that they spend less time in the Library as a result of using the Library by remote access.

On the other hand, $12.3 \%$ (27) of remote users reported using the Library less frequently in-house and the same number $12.1 \%$ (27) stated that they spend more time in the Library at each visit.

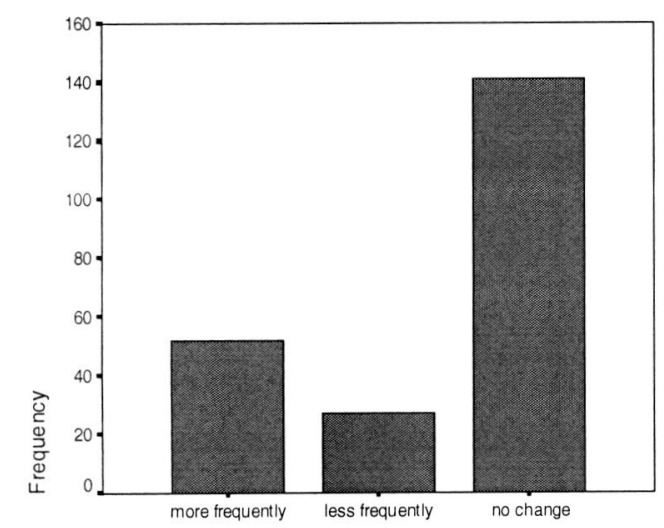

Chart 14: Changes to the number of in-house Library visits

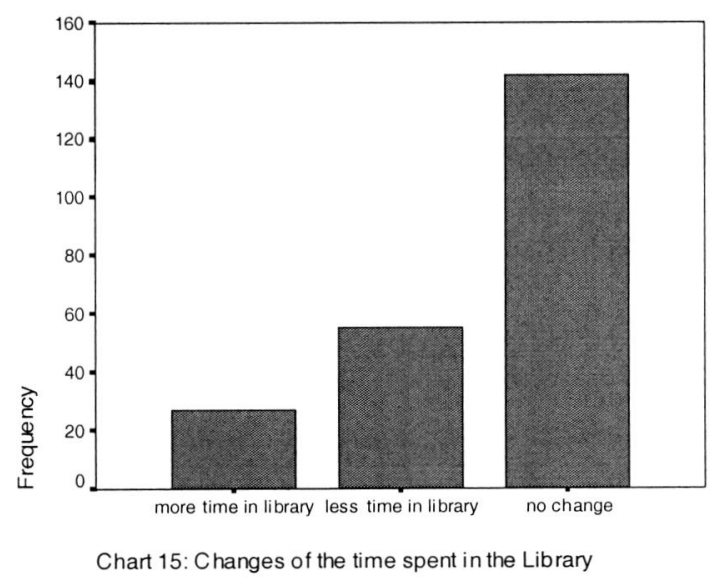

Table 13 below illustrates remote user behaviour described above in more detail.

For the majority of remote users $(87.9 \% ; 123)$ who did not change the frequency of their visits to the Library as a result of accessing the Library by remote access, the amount of time spend in the Library also did not change. $11.4 \%$ (16) spend less time and $.7 \%$ (1) more time in the Library. 
Of those respondents who visit the Library more frequently, the largest group (45.1\%; 23) also spend more time in the Library and nearly one-third $(31.4 \% ; 16)$ spend less time. $23.5 \%$ (12) spend the same length of time in the Library as before using remote access to the Library.

The majority of remote users $(84.6 \% ; 22)$ who visit the Library less frequently as a result of accessing the Library remotely also spend less time in the Library. 11.5\% (3) spend the same amount of time in the Library as before and 3.1\% (1) spend more time in the Library.

\begin{tabular}{|r|r|r|r|r|r|r|r|r|}
\hline & \multicolumn{4}{|c|}{ Amount of time spent in the Library } & \multicolumn{3}{c|}{ Table Total } \\
\cline { 2 - 8 } & \multicolumn{2}{|c|}{ more time } & \multicolumn{2}{c|}{ less time } & \multicolumn{1}{c|}{ no change } & \multicolumn{3}{|c|}{} \\
\cline { 2 - 9 } & Count & Row \% & Count & Row \% & Count & Row \% & Count & Row \% \\
\hline Visit the Lib more freque & 23 & $45.1 \%$ & 16 & $31.4 \%$ & 12 & $23.5 \%$ & 52 & $100.0 \%$ \\
less frequer & 1 & $3.8 \%$ & 22 & $84.6 \%$ & 3 & $11.5 \%$ & 27 & $100.0 \%$ \\
no change & 1 & $.7 \%$ & 16 & $11.4 \%$ & 123 & $87.9 \%$ & 141 & $100.0 \%$ \\
Table Total & 27 & $12.1 \%$ & 55 & $24.6 \%$ & 142 & $63.4 \%$ & 558 & $100.0 \%$ \\
\hline
\end{tabular}

Table 13: Changes to the frequency of visits and time spent in the Library by remote users

\subsubsection{Preparation of in-house Library visits by remote access}

\section{RQ 9: How often are in-house library visits prepared by remote use of the}

\section{Library?}

As illustrated by Chart 16 below, more than half $(56.3 \% ; 128)$ of all remote users prepared their visits to the physical Library either frequently $(16.7 \% ; 38)$ or occasionally $(39.6 \% ; 90)$ by accessing the Library's Web site remotely. 
$30 \%$ (68) of remote users prepare their library visits rarely and $13.7 \%$ (31) never prepare their visits to the Library by accessing the Library's Web site remotely.

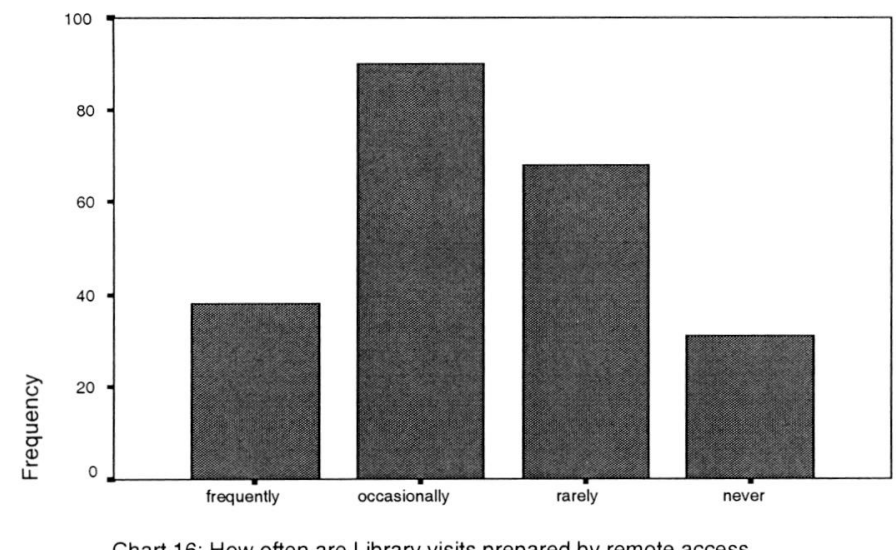

Chart 16: How often are Library visits prepared by remote access

Table 14 below illustrates further which groups of remote users prepare their visits to the Library by using remote access to the Library.

Over three-quarters of those who visit the Library more frequently $(78.8 \% ; 41)$ and those who visit the Library less frequently $(77.8 \% ; 21)$ as the result of using the Library's Web site by remote access prepare their visits to the physical library either frequently or occasionally.

On the other hand, over half $(56.4 \% ; 79)$ of those who did not change the frequency of visits to the Library as a result of remote access prepare their visits either rarely $(39.3 \% ; 55)$ or never $(17.1 \% ; 24)$.

The majority $(83.6 \% ; 46)$ of all respondents who spend less time in the Library as a result of accessing the Library by remote access prepare their visits either frequently or occasionally. Nearly three-quarters $(74.1 \% ; 20)$ of those who spend more time in 
the Library and $42.3 \%$ (60) of those whose time spent in the Library had not changed prepare their visits either frequently or occasionally.

\begin{tabular}{|c|c|c|c|c|c|c|c|c|c|}
\hline & \multicolumn{8}{|c|}{ Preparation of visits to the Library by remote access } \\
\hline & & \multicolumn{2}{|c|}{ Frequently } & \multicolumn{2}{|c|}{ Occasionally } & \multicolumn{2}{|c|}{ Rarely } & \multicolumn{2}{|c|}{ Never } \\
\hline & & Count & $\begin{array}{c}\text { Row } \\
\%\end{array}$ & Count & $\begin{array}{c}\text { Row } \\
\%\end{array}$ & Count & $\begin{array}{c}\text { Row } \\
\%\end{array}$ & Count & $\begin{array}{c}\text { Row } \\
\%\end{array}$ \\
\hline \multirow{3}{*}{$\begin{array}{l}\text { Frequency of } \\
\text { visits }\end{array}$} & More freq. & 13 & $25.0 \%$ & 28 & $53.8 \%$ & 5 & $9.6 \%$ & 6 & $11.5 \%$ \\
\hline & Less freq. & 7 & $25.9 \%$ & 14 & $51.9 \%$ & 5 & $18.5 \%$ & 1 & $3.7 \%$ \\
\hline & No change & 15 & $10.7 \%$ & 46 & $32.9 \%$ & 55 & $39.3 \%$ & 24 & $17.1 \%$ \\
\hline \multirow{3}{*}{$\begin{array}{l}\text { Time spent } \\
\text { in the Library }\end{array}$} & More time & 4 & $14.8 \%$ & 16 & $59.3 \%$ & 4 & $14.8 \%$ & 3 & $11.1 \%$ \\
\hline & Less time & 19 & $34.5 \%$ & 27 & $49.1 \%$ & 6 & $10.9 \%$ & 3 & $5.5 \%$ \\
\hline & No change & 14 & $9.9 \%$ & 46 & $32.4 \%$ & 58 & $40.8 \%$ & 24 & $16.9 \%$ \\
\hline Table Total & & 38 & $16.7 \%$ & 90 & $39.6 \%$ & 68 & $30.0 \%$ & 31 & $13.7 \%$ \\
\hline
\end{tabular}

Table 14: Frequency of visits, time spent in-house and preparation by remote access

\subsection{Training needs}

Chart 17 below illustrates training needs of remote and in-house only library users in relation to learning about how to use the Library's services and resources on the Internet.

Just over half $(54.6 \%$; 177) of in-house only users and just under half of remote users $(46.5 \% ; 105)$ stated that they would like training.

A chi-square test found a marginally statistical significant difference between remote users and in-house only users in their need for training $(\mathrm{p}=.059)$. 


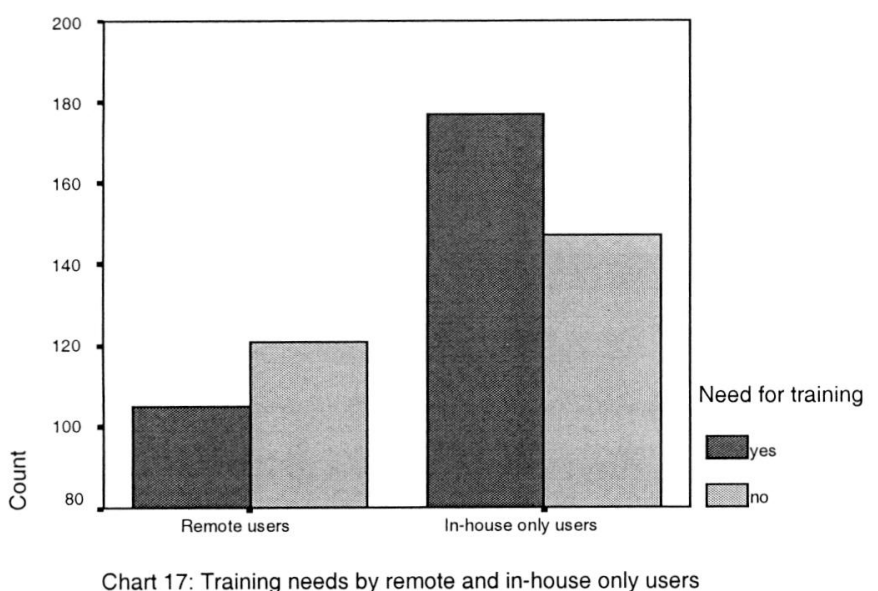

Table 15 below summarises the multiple responses given by most of those who wanted training on the use the Library's Web site. The majority of in-house only and remote users stated they want hands-on tutorials $(68.4 \%) .54 .3 \%$ would like guides and handouts, $34.8 \%$ online tutorials and $16.8 \%$ would like help by phone and email.

Compared to the remote user group, higher percentages of in-house only users prefer hands-on tutorials (7.2\% more) and guides/handouts (17.7\% more). On the other hand, higher percentages of remote users prefer on-line tutorials ( $23.7 \%$ more) and help by phone and email ( $2.9 \%$ more) compared to the in-house only user group.

\begin{tabular}{|lll|r|r|r|}
\hline & & \multicolumn{2}{|c|}{ Training needs } & \\
\cline { 3 - 5 } & & \multicolumn{2}{|c|}{$\begin{array}{c}\text { Remote } \\
\text { users }\end{array}$} & $\begin{array}{c}\text { In-house } \\
\text { only } \\
\text { users }\end{array}$ & \multicolumn{1}{|c|}{ Total } \\
\hline Training & Hands-on & Count & 62 & 113 & 175 \\
formats & tutorials & Column \% & 63.9 & 71.1 & 68.4 \\
& Guides/handouts & Count & 42 & 97 & 139 \\
& & Column \% & 43.3 & 61.0 & 54.3 \\
& Online tutorials & Count & 48 & 41 & 89 \\
& & Column \% & 49.5 & 25.8 & 34.8 \\
& Phone or email & Count & 18 & 25 & 43 \\
& & Column \% & 18.6 & 15.7 & 16.8 \\
Total & Count & & 97 & 159 & 256 \\
& Column \% & & 100.0 & 100.0 & 100.0 \\
\hline
\end{tabular}

Table 15: Preferred formats of training 


\section{Discussion}

\subsection{Population and sample}

The sample size is the strength of this study as nearly half $(49.8 \% ; 558)$ of the 1120 on-campus students currently enrolled in the selected programmes (see 3.2) participated in the survey and returned questionnaires which could be used in the study.

In comparing the demographics of the students in the sample with the whole population some differences between those two populations were found (see 5.1).

Male students were slightly under-represented. As the difference is small this should not affect the study.

Graduate students were over-represented and therefore also students in their fourth year and higher and students enrolled in the two GradDipT programmes. The sample had 4\% more GradDipT-Secondary students and 2.1\% more GradDipT-Primary students compared to the distribution of percentages in the whole population. There is also a higher percentage of male students among graduate students. This will have a minor effect on the study as a higher percentage of graduate students were found to use the Library by remote access than undergraduate students (see 5.3.3).

Generally the differences between the sample and the whole population should not distort the findings of this study as for most of the data analysis percentages within 
groups were used to compare different populations. For example, the percentage of males who use the library by remote access is compared with the percentage of females. Where the difference between the sample and the population was an issue in analysing the data this is mentioned in the study and taken into consideration.

In analysing the data it has also to be kept in mind that the sample of the Ropu Rumaki students is not complete, as no year 2 students of this programme were captured in the survey. This happened because Ropu Rumaki students were surveyed in the same classes as BTchg-Primary students.

In this study sample sizes of Ropu Rumaki students, BTchg-Hons. students and parttime students are very small, which limited the statistical analysis and statements which could be made about these groups and excluded these populations from chisquare tests (see 4.4).

\subsection{Internet access and the use of the Library's Web site}

As hypothesised, a greater number of on-campus undergraduate students $(37.7 \%$, see Table 3) were found to use the Library by remote access than reported in the literature (see 2.2.1).

The main reason is that Internet access for students, especially undergraduate students, has increased since those earlier studies. This study found that Internet use among students is high; $83.1 \%$ of the students surveyed use the Internet and $77.2 \%$ of 
those have Internet access at home (see 5.2). There is not much difference between undergraduate and graduate students who have Internet access at home (see Table 2).

In the literature review Snelson (1993) and other studies (see 2.3.3) found that convenient access, such as from home, is a major reason for using remote library services. This was confirmed by the findings of this study which found that $87.7 \%$ of undergraduate and $83.8 \%$ of graduate students who use the Library by remote access do so from home (see Table 6). In comparison only about one-third (34.1\%) of all remote users accessed the Library from a computer lab on campus.

Ferl and Millsap (1992) found in their study that $22.2 \%$ of on-campus students and staff accessed the Library from home (and dormitory) and $7.8 \%$ from a laboratory or computer centre on campus. Because Ferl and Millsap's (1992) study had a different sample (see 2.1) these figures cannot be compared. However, they do show how convenient access to the Internet at home and on campus has improved in recent years for the student population, especially for undergraduate students.

The computer lab in the School of Education (Media Centre) provides access to the Internet to every enrolled SOE student. Looking at the figures above it can be presumed that most students use the Library by remote access from home. Another reason why only about one-third of the students who use the Library by remote access do so from the Media Centre could be that the computer lab is located below the Library and therefore it is just as easy for students to go to the Library. 
Further reasons could be organisational: students have to pay extra for a swipe card to access to the Media Centre. They also have to pay for international Internet use. Use of the Library's services and resources available by remote access (see. 5.4.2) is free, with the exception of the use of international web sites available through the subject portals. This might not be known by all students.

This study found that less than half (41.4\%) of all students surveyed used the Library by remote access (see Table 3 ) and sought to determine the reasons why more than half of the students in the sample were not using remote access to the Library. 53.9\% of those students who used the Internet but not the Library by remote access provided reasons (see Chart 1).

The majority (44.7\%) of those who gave reasons stated either that they had "no need" to use the Library by remote access or said that they "rather go to Library". These two reasons are probably related. Because of the convenient location of the Library within the SOE and its closeness to the computer lab, it is just as easy for many students to visit the Library between or after classes.

In accordance with findings in the literature (see 2.3.1), this study also identified a lack of awareness among students regarding the Library's Web site and the services and resources offered by remote access. Just under one-third of those who gave reasons for not using the Library by remote access stated that they are not aware of the Library's remote services and resources. 
As identified by several studies in the literature review and confirmed by this study, there is a need for the continuous promotion of Library services and resources that become available by remote access. This can partly be achieved through offering training to on-campus students in a variety of formats to suit their individual needs (see 5.5). In line with findings in the literature (see 2.3.2), most students surveyed in this study preferred hands-on tutorials and some contact with library staff. However, guides, handouts and online tutorials are also important vehicles for increasing students' awareness of and skill in using the Library by remote access.

Lack of information about the Library's Web site was most likely also the reason why some students perceived they had no remote access to the Library, as stated by $15.4 \%$ (19) of those students who provided reasons. Only three of these students had Internet access at home. Maybe some students of this group meant they had no convenient access at home.

This study also investigated how long students have been using the Library by remote access and found that more than half (54\%) of all remote users started to use the Library by remote access from the beginning of this academic year (2001). Just over one-quarter of all remote users have been long term users of the Library's Web site.

A high proportion of the new users are young undergraduate students in the 16-21 age group. These students come to University with a high level of computer literacy and are heavy users of the Internet (see 5.3.2). Relating to findings in the literature review, more familiarity and a more positive attitude towards using computers has most likely 
increased students' readiness to use Internet-based library services and resources (see 2.2.2).

This study also found a high number of new users as well as long-term users among graduate students in their fourth or more year of study. The fact that both GradDipT programmes are one-year courses accounts for the new users. Some students come back to university for this course and started to use the Library's Web site at the beginning of the academic year. On the other hand, some graduate students who came to this course after finishing their undergraduate degree would have been continuously at the university and using remote library services while studying for their first degree.

Other reasons which might account for the high number of new users could be that more services and resources have become available by remote access fairly recently. Citation and full-text databases became available in B semester 2000. More full-text databases useful to SOE students were added to the collection at the beginning of 2001. Students increasingly realise they can access full-text documents at home using their own printer rather than pay for printing in the Library.

Finally, remote services and resources, especially checking borrower information through the catalogue, have been increasingly promoted by the Library, for example through the orientation programme, library assignments, tutorials, hand-outs, library guide, bookmarks and verbally in one-to-one encounters. This would have increased the number of students who are now using the Library by remote access. 


\subsection{Characteristics of remote users}

\subsubsection{Gender, age and status}

This study found statistically significant differences between gender and Internet use and Web site use respectively. Just over half of all male respondents and just over one-third of all female respondents use the Library by remote access. A greater proportion of male students are long-term users of the Library's Web site (see 5.3.1)

This is partly due to the uneven distribution of male remote users across the programmes, age levels and accordingly year of study and status. In comparing the col $\%$ in Table 4 , the data show that a higher proportion of male remote users are graduate students, between 22-34 years old and much higher proportions are enrolled in the BTchg-Secondary Cojoint and GradDipT-Secondary programmes (see Table 4).

On the other hand, most female remote users are in the 16-21 or the 35-44 age groups. More female remote users use the Library by remote access from home compared to male remote users. This might indicate that the older women have family commitments and use remote access to the Library as a convenient way to study while they have to be at home. For them convenient access is important.

The high proportion of male students in graduate programmes raised the question of whether the statistically significant difference between genders found in this study (see 5.3.1) is due to the fact that half $(50.8 \%)$ of all male students surveyed are graduate students, who are using the Library significantly more by remote access than undergraduate students (see 5.3.3). Further analysis of the data, which involved 
looking at both gender groups separately and comparing the percentages of male and female remote users in each year of study ${ }^{20}$, showed that higher percentages of male students in each level were using the Library by remote access. The study therefore found that there is a gender difference and that a greater proportion of male than female students are inclined to use the Library by remote access.

Statistically significant differences were also found between the age categories and Internet use and remote use of the Library respectively. The use-patterns in Chart 4 show that Internet use is highest among younger students and use of the Library by remote access by older students.

This study found the 28-34 age group were the most intensive users of the Library's Web site and the Internet in general. The reason is that this group has the highest proportion of male users and nearly half are graduate students who have been studying four years or more.

The older age groups, especially $28-44$ year olds, also have slightly more convenient Internet access from home, which could be a factor of increased use of the Library's Web site. Again there might be more need for older students to use the Library from home because of family commitments (see Table 5).

Ferl and Millsap (1992) found a similar pattern among students and staff of the University of California who used the library by remote access. In their study the 25

\footnotetext{
${ }^{20}$ In year $1,30.4 \%$ were female and $36.1 \%$ were male students, in year $2,50 \%$ were female and $72.2 \%$ were male students, in year $3,28.6 \%$ were female and $37.5 \%$ were male students and in year $4+, 47.7 \%$ were female and $61.2 \%$ were male students of all students surveyed who used the Library by remote access.
} 
to 34 age group constituted the highest user group of remote library services followed by 35 to 44 year olds (Ferl and Millsap 1992, 290). Dow (1991), who surveyed individuals ${ }^{21}$ between 15 and 65 years, also found that $78 \%$ of respondents were between 25 and 54 years old (Dow 1991, 217).

Keeping in mind that both Dow (1991) and Ferl and Millsap (1992) surveyed different populations compared to this study, it is interesting that all three studies found that the youngest age group are not the most intensive remote library users. This group comprised just under half (46.2\%) of all students surveyed in this study.

This study found that most of the youngest age group are Internet users and that fourfifth of them have convenient Internet access at home. One reason could be that these mostly undergraduate students do not feel the same need to use the Library by remote access as the older students and graduate students, who have family commitments and pressures from a more intensive programme. However, this study found that more young undergraduate students mainly enrolled in the BTchg-Primary programme tended to start using the Library by remote access in their first year of study (see Table 8). There were also many new users of the Library's Web site by remote access in this age group.

A greater statistically significant proportion of graduate students use the Library's Web site by remote access compared to the percentage of undergraduate students (see 5.3.3). This is consistent with findings of Ferl and Millsap (1992).

\footnotetext{
${ }^{21}$ MUG newsletter readers, who used the Penn State University's library system (LIAS) by remote access
} 
It has to be kept in mind that access to the Internet for undergraduate students has very much improved since 1992 (see 5.2). This study found that a slightly higher proportion of undergraduate students has Internet access at home in addition to students' access to the Internet in the computer lab and the Library.

It also needs to be noted that the majority of graduate students surveyed in this study (except for students enrolled in BTchg-Hons) are not doing post-graduate studies which would involve more intensive library research and a greater need to use the databases which could be accessed from home. Remote use of the databases was higher among undergraduate students (see Table 10).

Possible reasons why both studies found that graduate students are heavier users of remote library services could be that these students have been longer users of the university library and they are enrolled in more demanding programmes. Because of greater time constraints, graduate students might have a greater need to use the Library by remote access independent of library opening hours etc.

\subsubsection{Year of study, programme and full-time/part-time study}

This study found statistically significant differences between year of study and Internet and remote library use. Remote use of the Library generally increases by year of study as shown in Chart 6.

The exception are year 3 students who are high users of the Internet but very low users of the Library by remote access (29.2\%) in comparison to year 2 students 
$(53.5 \%)$. Year 3 students also have the highest access to the Internet at home. There is probably a combination of reasons why year 3 students do not follow the pattern.

One reason for their low use of the Library by remote access could be that male students, who were previously shown to use the Library more by remote access, are under-represented in year 3. A total of eight (7.2\%) male students appeared in the year 3 sample, three of whom use the Library by remote access.

Further analysis of the data showed that over half $(53.1 \% ; 17)$ of year 3 students who gave reasons why they do not use the Library's Web site stated that they do not know about it, and just under $10 \%$ thought they have no access. Even though the sample is small $(\mathrm{N}=32)$ a lack of awareness of and information about the Library's remote resources and services seems to be the main reason why not many year 3 students use the Library by remote access. When these students started their study the Library's Web site was less actively promoted and there were fewer library services available by remote access. The Library did not provide remote access to the databases at that time and the web-based catalogue was also not available in-house.

Another reason for the low use of the Library by remote access by year 3 students could be that if they had not used the Library by remote access previously they do not perceive a need to start using remote access in their last year of study. As one year 3 student commented: "I don't need this [remote access to the Library] now, I have nearly finished". This could also be the main reason for the $28.1 \%$ of year 3 students who provided reasons for not using the Library by remote access who stated that they do not need remote access to the Library or that they rather go to the Library. 
The study found that there is a statistically significant difference between the different programmes and the use of the Library by remote access. The sample sizes of the BTchg-Hons and Ropu Rumaki programmes are very small and any statement made here must be treated with caution.

Surprisingly students enrolled in the BTchg-Hons programme, who were the only group doing post-graduate studies, were not high users of the Library by remote access and had not the same characteristics found in other graduate students surveyed who are heavy users of remote library services (see Chart 7).

Ropu Rumaki students surveyed had the lowest access to the Internet at home, which could be a reason why only five students used the Library by remote access. As the sample was small and year 2 students were missing this finding needs to be treated with caution.

Most programmes show a pattern of steady increase of remote Library use from the first to the second year (see Table 8). This could be expected as students in their first year of study are still getting used to studying and to the University Library. It could also be that initially new undergraduate students prefer "human contact and gravitate toward on-site use of library services" as stated by Clougherty (Clougherty et al. 1998, 582). When they reach their second year, most students are confident in-house library users which allows them to explore library services and resources by remote access. 
Students enrolled in the BTchg-Primary programme have a high percentage of year 1 students using the Library by remote access and this stays at the same level in their second year of study. This could be for the reason mentioned before, that new undergraduate students coming to University are more sophisticated computer and Internet users which enables them to start using the Library by remote access straight away.

The sample size of part-time students was also too small to support any valid conclusions. Generally part-time students' use-pattern of the Library's Web site by remote access did not differ much from that of full-time students. The reason why so few part-time students were captured in the sample must be because part-time students structure their study differently and only one compulsory class at each level in each programme was surveyed.

\subsection{Impact of remote Library use on the use of the Library in-house}

This study asked whether remote library use has an impact on the use of the physical library. To determine this it compared user behaviour of remote users and in-house only users in relation to their use of library services and resources in-house, frequency of visits to the Library and time spent in the Library. Remote users were also asked if they had made any changes in using the Library in-house (frequency of visits and time spent) since they began using the Library by remote access and if they used remote access to prepare their visits to the physical Library. 
The study found some clear differences between the remote and in-house only user groups in their use of the physical library.

Apart from study/group study, which is used less by a small percentage of remote users $(1.3 \%)$, all other library services and resources are used by higher percentages of remote users (see 5.4.1).

The greatest gaps between remote and in-house only users were found in those services and resources which can also be used by remote access, such as the catalogue and all the functions available through the catalogue (recalls, borrower information), use of the databases and the Internet (see 5.4.2). This could be expected to some extent as the remote user group will probably be more familiar with these services and resources and find them easier to use.

However, a substantially higher proportion of remote users (10.3\% more) also browse the library shelves compared to in-house only users. Taking into account that higher percentages of remote users also use most other library services and resources inhouse, this could be an indication that generally the remote user group are heavier library users.

Only two $(.9 \%)$ remote users stated they never use the Library in-house, which indicates that remote access to the Library is used in addition to in-house Library use, to enhance the library visit rather than to replace it. It has to be kept in mind that this is partly due to the nature of the study programmes surveyed and the need for teacher trainee students to access physical library resources (see 3.1). 
In further comparing the remote user group with in-house only users this study found a statistically significant difference between these two groups in the frequency of inhouse library visits but not in the amount of time spent in the Library on average at each visit (see 5.4.3).

The sample size for these two questions is slightly smaller $(\mathrm{N}=525$ and $\mathrm{N}=521$ respectively), because around $6 \%$ of respondents failed to provide answers. This has to be kept in mind, but as the sample is still large this should not affect the validity and interpretation of the data.

More remote users were found to visit the Library daily in-house (9\% more) and on a monthly basis ( $4.8 \%$ more), whereas a greater percentage of in-house only users (11.3\% more) come in on a weekly basis (see Table 11). Remote users stayed about the same length of time in the Library as in-house only users (see Table 12).

As the frequency of visits to the Library has a wider distribution among the remote user group, it can be presumed that the availability of remote access causes some students to increase their visits to the physical library and some to decrease the number of visits. This pattern was also confirmed by statements of the remote user group about changes they made to their use of the Library in-house as a result of using the Library by remote access (see Chart 14 and 15).

In a more detailed analysis the study found that more remote users who come to the Library for a short time visited monthly or less and a greater percentage who visit the 
Library daily stay for either up to one hour or more than one hour. The differences between both user groups are illustrated in Chart 9 and 10.

Again, the trend shown here is that some remote users are heavier in-house library users as they visit the Library more often and stay longer $(70.7 \%$ of all remote users who visit the Library daily and stay for more than 30 minutes compared to $41.4 \%$ of in-house only Library users). A smaller percentage have reduced their use of the Library in-house as they come in less often and for shorter visits compared to inhouse only Library users (16.2\% remote users who visit monthly or less stay for up to 30 minutes compared to $10.6 \%$ of in-house only users).

The survey found that the majority of remote users access the Library's Web site weekly, monthly or less for up to 30 minutes (see 5.4.4, especially Chart 13). This use-pattern also confirms that the majority of remote users use remote access to the Library to supplement their visits in-house. The sample for this analysis was also slightly smaller $(\mathrm{N}=190)$ because of missing data.

The trend described above was also confirmed by statements remote users made concerning changes they had made since beginning to use the Library by remote access.

The majority $(64.1 \%)$ of remote users stated they did not change number of visits to the Library in-house or the time spent in the Library (63.4\%) as a result of accessing the Library remotely (see 5.4.5). 
Both Dow (1991) and Ferl and Millsap (1992) found similar figures concerning the frequency of visits to the library (see 2.1). $62.7 \%$ of respondents to Dow's survey and $62 \%$ of repondents in Ferl and Millsap's study did not change the frequency of visits to the library as a result of using the library by remote access. This figure seems to have stayed remarkably constant in the past 14 years. The most likely reason for this is that remote use is still used additionally but not instead of visits to the Library by the majority of remote users.

As Dow (1991) theorised in her study, remote access to the library is primarily used for quick bibliographic checks (Dow 1991, 220). Since then remote access to more services, especially to full-text databases, has become available. This allows remote users to find and read articles on-line instead of coming to the library and could reduce the frequency of visits to the library.

The reasons why this has not been found to be the case in this study are probably that full-text databases have become available only recently and that teacher trainee students need to use physical library resources.

Both Dow (1991) and Ferl and Millsap (1992) found that there was a trend towards using the library less frequently as a result of having remote access to the library. $29.8 \%$ of respondents to Dow's study and $26.5 \%$ of respondents to Ferl and Millsap's study stated they use the library less in-house. On the other hand $7.4 \%$ of respondents in Dow's study and $8.5 \%$ of respondents in Ferl and Millsap's study stated they use the library more in-house. 
This trend was not verified in this study. In accordance with Heller's (1992)

assumption that remote access to the library increased the use in-house, this study also found that nearly twice as many respondents (23.6\%) said they are using the Library more often in-house compared to $12.3 \%$ who use the Library less often.

This could partly be due to local conditions (see 3.1) and the fact that some remote services have been recently introduced. But in accordance with other findings in this study, it can also be assumed that a proportion of remote users are keen in-house library users who use remote access to enhance their use of the Library in-house. The proportion of remote users $(12.3 \%)$ in this study who follow the trend found by Dow and Ferl and Millsap is much smaller (see above).

Dow also found that $40.6 \%$ of respondents to her study spend less time studying and browsing in the library. In comparison this study found that there was no statistically significant difference in time spent in the physical library between the remote and inhouse only user groups (see 5.4.3). To the contrary, in this study a greater proportion of remote users were found to browse the shelves and there was not much difference between remote and in-house only users who are using the Library to study.

When comparing the results of these three studies it has to be kept in mind that the populations and user-needs are different in each study and therefore results cannot be directly compared. But with that qualification trends can be contrasted.

This study also found that nearly half of those who visit the Library more frequently also spent more time in the Library and nearly one-third spend less time in-house. 
Nearly all $(84.6 \%)$ of those who visit less frequently also spend less time in the Library and most of those who did not change the frequency of visits also did not change the amount of time spent in the Library. Those who changed the frequencies of their visits most often also prepared their visits to the Library by accessing the Library remotely (Table 14).

This confirms the trend identified throughout this study, that a proportion of remote users who made changes to their use of the Library in-house as a result of accessing the Library remotely have become more intensive library users. A second trend followed by a smaller group of remote Library users is that some remote users have become more time-efficient in their use of the Library in-house in preparing their visits by remote access. As one student commented: "outside [remote] access is a great time saver".

The second hypothesis for this study states that no clear pattern can be determined proving that remote use of Internet-based library services and resources by on-campus students has an impact on how students use the library in-house.

Looking at the findings discussed above, the hypothesis holds true. This study could only identify trends, such as the increased use of services and resources in-house by some remote users and the increased or reduced time spent in the library through preparation of visits to the library by remote access. However, this study cannot make a clear statement about whether and in which way the use of the physical library is impacted by remote use. The findings in this study certainly imply that remote use of the Library has a predominantly positive effect on in-house use of the Library. 


\section{Conclusion}

This study had two major research objectives as described in the problem statement:

- To determine the number and characteristics of on-campus students of the School of Education, University of Waikato who use the Library by remote access through the Library's Web site; and

- To examine if remote use of the Library by on-campus students has an impact on how these students use the Library in-house.

As hypothesised a greater number of undergraduate on-campus students were using the Library by remote access as predicted by the literature.

Even though the study found that more higher level and older students are heavier users of the Library by remote access, indications are that the number of younger and lower level students are increasingly using the Library by remote access. Many of these students were found to be new users of the Library's Web site.

Contrary to findings of earlier studies, this study found that there is no longer much difference between on-campus students of the different levels and status and Internet access at home. Convenient access to the Internet especially for undergraduate students has much improved which is the prerequisite for these students using the Library by remote access. 
As hypothesised no clear pattern could be determined proving that remote use of Internet-based library services and resources by on-campus students had an impact on how students use the library in-house.

In line with previous studies, this study found that over $60 \%$ of all remote users stated that using the Library by remote access did not change how they use the Library inhouse. The remainder of remote users stated they had made changes. Twice as many reported using the Library more compared to those who are using the Library less. Other findings of this study confirmed that some remote users are heavier users of the Library in-house whereas a smaller number are using the Library less in-house. In comparing the remote user group with in-house only library users, higher percentages of remote users were using nearly all library services and resources in-house and were visiting the Library more often on a daily basis or on a monthly basis.

Most remote visits to the Library were found to be brief and less frequent, which indicates that remote use to the Library is used complementary to in-house library use, for example to prepare a library visit or check the borrower information. This pattern was also confirmed by the small number of on-campus students who stated they use the Library only by remote access.

Although it is important to take into account that the outcome of this study was most definitely influenced to some degree by local conditions (see 3.1), the study found some clear tendencies of remote user behaviour which need to be investigated further, for example by surveying a different population. 
Ten years ago Elizabeth Dow predicted that "within 30 years the dial-up trade will be more important in academic library use than the walk-in trade" (Dow 1991, 225).

Within a fast changing environment characterised by increased and faster Internet access available to students, an ever increasing number of full-text documents available by remote access and a greater number of students studying by distance, it remains to be seen whether this statement will be true for on-campus students.

Findings from this study indicate that visits to the Library in-house by on-campus students are still far from being superseded by remote use of the Library.

Finally it is hoped that one outcome of this study was that on-campus students who participated in the survey are now better informed about the Library services and resources which are available by remote access. 


\section{Recommendations for further research}

- As the outcome of this study was influenced by local conditions in some areas and therefore cannot be generalised, further research using different and/or more diverse samples of the student population is needed to see if trends identified in this study are supported. This study could be used as a pilot study.

- More research is needed to examine the attitudes of academic staff towards remote use of the library and to monitor remote use of library services and resources by academic staff. Findings in the literature suggest that young computer-literate undergraduate students are faster adopters of remote library services than academic staff. Only if academic staff are users of remote library services themselves will they promote them to students (see 2.2.2).

- Further research should be conducted into the training needs of students and academic staff and to ascertain how training could best be delivered to suit the diverse user needs. Training needs were examined only as a side issue in this study. However, this study identified that there is a substantial need for training to help students to efficiently and effectively use the library services and resources by remote access. Remote library services are also promoted by including them in training programmes. 
- As remote library services and resources increase, for example e-reference and more full-text documents, ongoing research which monitors how on-campus students use the library by remote access and in-house will show if trends identified in this study continue. 


\section{Bibliography}

Adams, Judith A., and Sharon C. Bonk 1995. Electronic information technologies and resources: use by university faculty and faculty preferences for related library services. College and Research Libraries. 56 (2): 119-131.

Berger, Kenneth W., and Richard W. Hines. 1994. What does the user really want? The library user survey project at Duke University. Journal of Academic Librarianship 20 (5/6): 306-310.

Bushallow-Wilbur, Lara, Gemma de Vinney, and Fritz Whitcomb. 1996. Electronic reference service: A study. $R Q 35$ (3): 359-371.

Bydder, Jillene, and Nicola Harwood. 1998. Student expectations of, and satisfaction with, the university library. Journal of Academic Librarianship 24 (2): 161 172.

Clougherty, Leo, John Forys, Toby Lyles, Dorothy Persson, Christine Walters, and Carlette Washington-Hoagland. 1998. The University of Iowa libraries' undergraduate user needs assessment. College and Research Libraries 59 (10): $572-584$.

Dow, Elizabeth H. 1991. The impact of home and office workstations on use of an academic library. Advances in the implementation and impact of computer systems 1: 211-232. 
Ferl, Terry Ellen, and Larry Millsap. 1992. Remote use of the University of California Melvyl library system: An online survey. Information Technologies and Libraries. 11: 285-303.

Heller, Paul. 1992. Remote access: Its impact on a college library. Electronic Library 10 (5): 287-289.

Hsieh-Yee, Ingrid. 1996. Student use of online catalogs. College and Research Libraries 57 (2): 161-175.

Kalin, Sally W. 1991. Support services for remote users of online public access catalogs. $R Q 31: 197-213$.

Liebscher, Peter, Eileen G. Abels, and Daniel W. Denman. 1997. Factors that influence the use of electronic networks by science and engineering faculty at small institutions. Part 2. Preliminary use indicators. Journal of the American Society for Information Science 48 (6): 496507.

Maughan, Patricia Davitt. 1999. Library resources and services: A crossdisciplinary survey of faculty and graduate students use and satisfaction. Journal of Academic Librarianship 25 (5): 354-366. 
McCarthy, Ann Cheryl, Sylvia C. Krausse and Arthur A. Little. 1997. Expectations and effectiveness using CD-ROMs: What do patrons want and how satisfied are they? College and Research Libraries 58(2): 128-142.

Millsap, Larry, and Terry Ellen Ferl. 1993. Search patterns of remote users: An analysis of OPAC transaction logs. Information Technology and Libraries. 12: $321-343$.

Poll, Roswitha, and Peter te Boekhorst. 1996. Measuring quality: International guidelines for performance measurement in academic libraries. Muenchen: K. G. Saur.

Rhodes, Helen, and Jacqueline Chelin. 2000. Web-based user education in UK University libraries- Results of a survey. Program 34 (1): 59-73.

Rockman, Ilene F. 1998.Challenges and opportunities in reaching the remote user. In Recreating the academic library: Breaking virtual ground, ed. Cheryl LaGuardia, 241-255. New York: Neal-Schuman Publishers, Inc.

Schlichter, Doris J., and J. Michael Pemberton. 1992. The emperor's new clothes? Problems of the user survey as a planning tool in academic libraries. College and Research Libraries 53 (2): 257-265.

School of Education. 2001. Undergraduate programmes handbook. Hamilton: University of Waikato. 
Snelson, Pamela. 1993. Relationship between access and use in information systems: Remote access to and browsing of online catalogs. Proceedings of the $56^{\text {th }}$ ASIS annual meeting. 30: 73-79.

Starkweather, Wendy M., and Camille Clark Wallin. 1999. Faculty response to library technology. Library Trends 47 (4): 640-669.

Vander Meer, Patricia, Howard Poole, and Thomas Van Valey. 1996. The connection between library use and use of campus computer applications. Electronic Library 14 (4): 339-346.

Vander Meer, Patricia, Howard Poole, and Thomas Van Valey. 1997. Are library users also computer users? A survey of faculty and implications for services. Public Access Computer Systems Review 8 (1): 1-17. Available under: http://info.lib.uh.edu/pr/v8/nl/cont8n1.html [Accessed 3/09/2000]

Weingart, Sandra J., and Janet A. Anderson. 2000. When questions are answers: Using a survey to achieve faculty awareness of the library's electronic resources. College and Research Libraries 61(2) : 127-134. 


\title{
Appendix 1
}

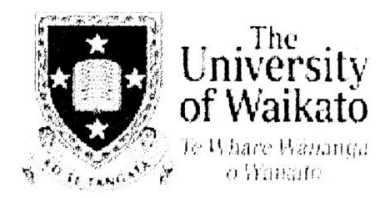

\section{Dear students}

This questionnaire is designed to find out if and how some library services and resources are used by students. Please answer 20 short questions. This will take about 3-5 minutes.

The survey is done as part of my degree at Victoria University of Wellington towards the Master of Library and Information Studies (MLIS) and as a feedback and planning tool for the Library in order to improve the Library's services to you. My supervisor is Dr. Dan Dorner at Victoria University. He can be contacted by email (dan dorner@vuw ac nz) or by phone (04-4635781).

The questionnaire is completely anonymous and has been approved by the Ethics Committee of Victoria University.

Please place the completed questionnaires into the return box provided.

If you are interested in the results, please contact me. The questionnaires will be destroyed six months after the research is completed.

\section{Thanks for your time. Your help is appreciated.}

Signed

\author{
Angela Broring \\ Education Library \\ Phone: 8384530 \\ Email: abroring@waikato.ac.nz
}


A. What is your current status?

Undergraduate

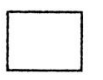

Graduate

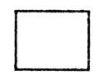

B. Please state your year of study:

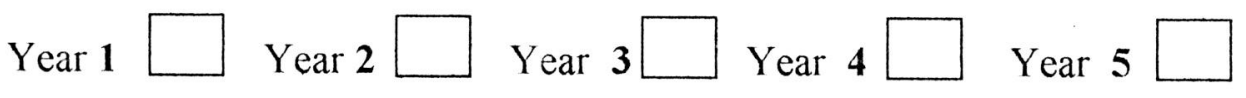

$\square$ Other, please state

C. Which programme are you enrolled in:

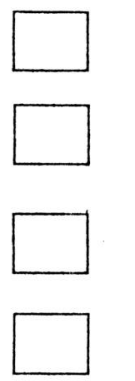

BTchg - Early Childhood

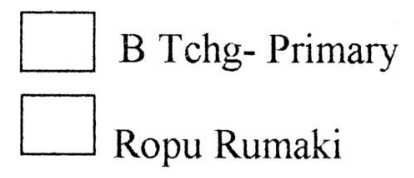

B Tchg Secondary Cojoint

Grad DipT-Primary

Grad DipT-Secondary

B Tchg (Hons)

Other, please state

D. Do you study

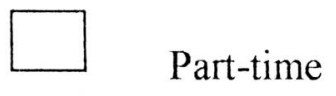

Part-time

Full-time

E. Do you use the Internet?

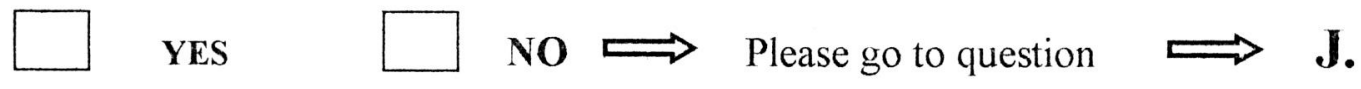

F. Where do you access the Internet?

(Please tick all boxes applicable)
$\square$ Home
$\square$ Computer lab on campus
$\square$
Library
$\square$ Work
Other, please state

G. Have you used the University of Waikato Library's resource/services (for example the catalogue) through the Library's Web site ( http://www.waikato.ac.nz/library/) from outside the Library?

\section{YES}

NO, please state reasons

Please go to question

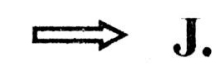


I. Please state for how long you have been using the Library's services/resources through the Library's Web site from outside the Library:
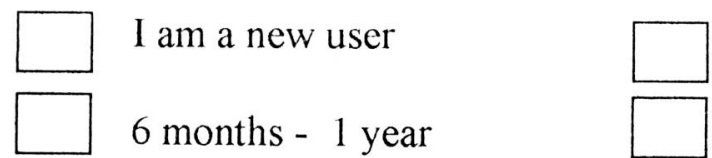

1-3 months more than 1 year

J. Please state which Library services/resources you use in the Library: (Please tick all boxes applicable)

$\square$ None

$\square$ Search for materials on the shelf

$\square$ Use the reference collection

$\square$ Use the Internet

$\square$ Interloan items

$\square$ Desk copy

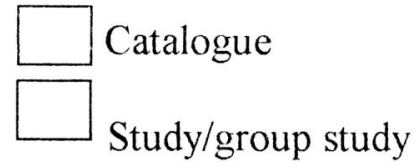

Consult librarian

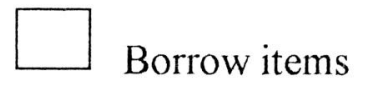

Recall items

Photocopy

$\square$ Databases and full-text journals through LibraryLink

Check borrower information/renewals/requests

Other, please state

K. Please state which library services/resources you use through the Library's Web site from outside the Library (Please tick all boxes applicable)

$\square$ None

$\square$ Catalogue

$\square$ Recalls

Databases/Full-text journals through LibraryLink

$\square$ Check borrower information/renewals/requests

Other, please state 
L. How often do you use library services/resources in the Library and/or from outside the Library through the Library's Web site on the Internet?

(Please tick all boxes applicable)

\section{In the Library}

Daily

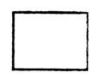

From outside the Library

Weekly

Monthly
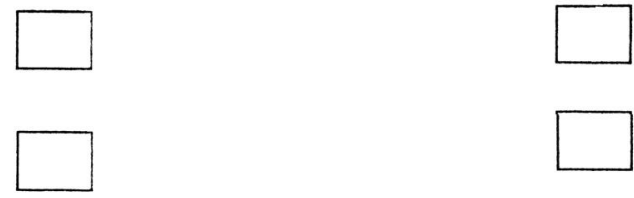

Rarely
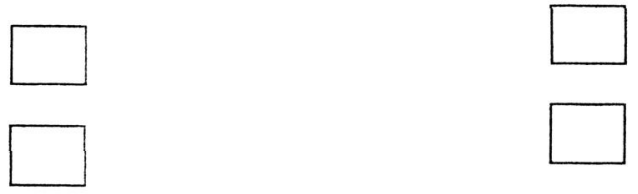

Never
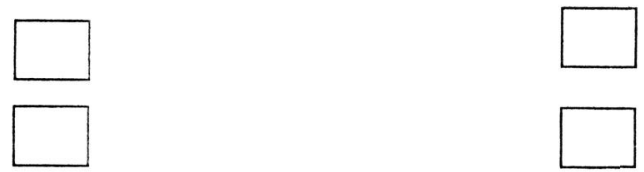

M. On average, how much time do you spend using the Library's services/resources in the Library and/or from outside the Library through the Library's Web site at each visit?

(Please tick all boxes applicable)

In the Library

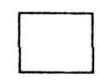

Up to 15 minutes

Up to 30 minutes

Up to 1 hour

1-2 hours

More than 2 hours
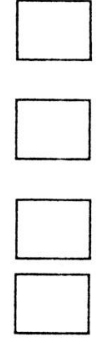

From outside the Library
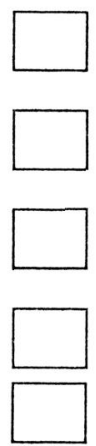

IF you DO NOT use the Library's resources/services through the Library's Web site from outside the Library, please go to question Q.

N. Since you use the Library's Web site to access library services/resources the from outside the Library, on average do you:

$\square$ Visit the Library more frequently

$\square$ Visit the Library less frequently

$\square$ No change in frequency of visits 
O. Since you use the Library's services/resources through the Web site from outside the Library, on average do you:

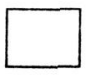

Spend more time in the Library

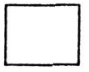

Spend less time in the Library

$\square$ No change of the amount of time spent in the Library

P. How often do you prepare your visit to the Library by accessing the Library's Web site first from outside the Library?

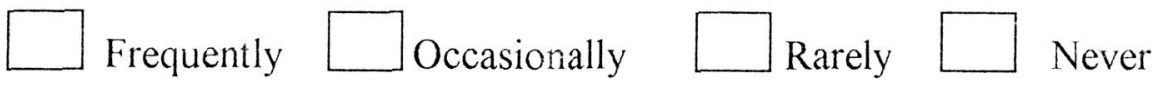

Q. Would you like training to use the Library's services/resources on the Internet?

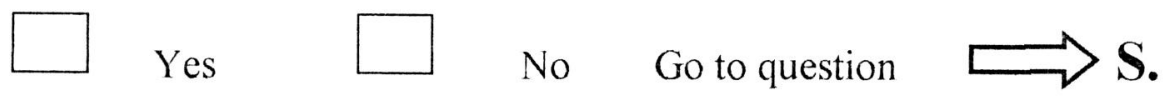

R. How would you like to receive training (please tick all appropriate boxes)

$\square$ Practical hands-on group demonstration $\quad \square$ Guides/handouts
in the Library's tutorial room

Computer-based tutorials on the Library's Web site

Help by phone or email

Other, please state

S. Which age category applies to you?

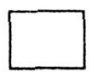

$16-21$

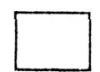

$22-27$

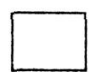

28-34

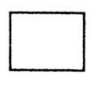

$35-44$

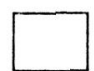

45 years and over

T. Are you

Female

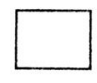

Male

U. Are there additional library services/resources which you would like to have available either within the Library and/or from outside the Library through the Library's Web site? Do you have any other comments? Please state:

Thank you for your time! Please return the completed questionnaire in the return box before you leave. 
School of Education statistics (on-campus students only)

\begin{tabular}{|c|c|c|c|c|c|c|c|c|c|c|c|c|}
\hline \multirow[t]{2}{*}{ Programme } & \multicolumn{3}{|c|}{ Year 1} & \multicolumn{3}{|c|}{ Year 2} & \multicolumn{3}{|c|}{ Year 3} & \multicolumn{2}{|c|}{ Year $4+$} & \multirow[t]{2}{*}{ Total } \\
\hline & $\mathrm{F}$ & M & Total & $\mathrm{F}$ & M & Total & $\mathrm{F}$ & M & Total & $\mathrm{F}$ & M & \\
\hline BTchg-Primary & 166 & 50 & 216 & 164 & 49 & 213 & 174 & 23 & 197 & & & 626 \\
\hline BTchg-Secondary Cojoint & 11 & 10 & 21 & 14 & 10 & 24 & 52 & 24 & 76 & & & 121 \\
\hline BTchg-Early Childhood & 45 & - & 45 & 52 & 1 & 53 & 40 & - & 40 & & & 138 \\
\hline Ropu Rumaki & 13 & 5 & 18 & 13 & 3 & 16 & 16 & 9 & 25 & & & 59 \\
\hline GradDipT-Primary & & & & & & & & & & 47 & 31 & 78 \\
\hline GradDipT-Secondary & & & & & & & & & & 49 & 36 & 85 \\
\hline BTchg-Honours & . & & & & & & & & & 12 & 1 & 13 \\
\hline
\end{tabular}

\section{* Figures are from April 2001}

Total: 1120

$\frac{N}{2}$ 